\section{Pathological basis of symptoms and crises in sickle cell disorder: implications for counseling and psychotherapy}

\section{Oluwatoyin Olatundun Ilesanmi}

Behavioural Studies Department, College of Management Sciences, Redeemer's University, Mowe, Ogun State, Nigeria

\begin{abstract}
Sickle Cell Disorder (SCD) is a congenital hemoglobinopathy. There is little in literature regarding the psychological variables affecting individuals living with SCD and all of the significant people around them. There are also limited numbers of trained clinical psychologists and genetic counselors to cater for the psychotherapeutic needs of individuals living with SCD. Even among those who have been trained, only a few might have fully grasped the complexities of the disease pathology.

Early understanding of its pathological nature, sources, types, complications, pathophysiological basis, and clinical severity of symptoms among clinical psychologists, genetic counselors and psychotherapists, as well as general medical practitioners, could guide them in providing holistic care for dealing with and reducing pain among individuals living with SCD. It could allow risk-based counseling for families and individuals. It could also justify the early use of disease-modifying or curative interventions, such as hydroxyurea (HU), chronic transfusions (CTs), or stem-cell transplantation (SCT) by general medical practitioners. Hence, the need for this paper on the pathophysiology of SCD.
\end{abstract}

\section{Introduction}

Sickle cell disorder (SCD), also known as drepanocytosis, is a quadrumvirate of anemia and its sequelae, pain syndromes, organ damage including infection, and comorbid conditions. ${ }^{1-6}$ It is a chronic blood disorder characterized by red blood cells that assume an abnormal, rigid, sickle shape. The striking deformity of the red blood cells led to the disorder being termed 'sickle cell anemia' ${ }^{7}$ and 'sickle cell disease', ${ }^{8}$ names that reflected the subsequent acceptance that erythrocyte distortion was central to the development of its symptoms. In 1917, Emmel noted that the degree of erythrocyte deformation varied with time $^{9}$ and Hahn and Gillespie ${ }^{7}$ demonstrated that this eponymous change was induced by deoxygenation.

This disorder usually presents early in childhood and affects millions throughout the world. It occurs more commonly in people (or their descendants) from parts of tropical and sub-tropical regions where malaria is or was common. One-third of all aboriginal inhabitants of Sub-Saharan Africa, Spanish-speaking regions (South America, Cuba, Central America), Saudi Arabia, India, and Mediterranean countries such as Turkey, Greece, and Italy, carry the gene.* This is because in areas where malaria is common, there is a survival value in carrying only a single sickle-cell gene (sickle cell trait). ${ }^{\circ}$ Those with only one of the two alleles of the sickle cell disorder are more resistant to malaria, since the infestation of the malaria plasmodium is halted by the sickling of the cells which it infests. In the US, it affects around 72,000 people, most of whose ancestors come from Africa. ${ }^{6}$ The disorder occurs in about 1 in 500 African-American births and 1 in 1,000-1,400 Hispanic-American births. About 2 million Americans, or 1 in 12 African Americans, carry the sickle cell trait. SCD is considered the most common monogenic disease in Brazil.

As a generation of individuals with sickle cell disorders and thalassemia ages, new chronic complications of these hemoglobinopathies develop, several of which are potentially lethal and clinically multi-systemic with a great variability of manifestations modulated by genetic and environmental factors. Early understanding of its pathological nature, sources, types, complications, pathophysiological basis, and clinical severity of symptoms among clinical psychologists, genetic counselors and psychotherapists, as well as general medical practitioners, could guide them in providing holistic care for dealing with and reducing pain among individuals living with SCD. However, there is little in literature concerning the psychotherapeutic management of symptoms and crises of SCD. There are also limited numbers of trained clinical psychologists and genetic counselors to cater for the psychotherapeutic needs of individuals living with the disease. Even among those who have been trained, only a few of them might have fully grasped the complexities of the pathology of SCD. Hence, the need for this paper.

\section{Types of sickle cell disorder}

Sickle cell disorder denotes all genotypes that contain at least one sickle gene in which

\author{
${ }^{\circ}$ Sicklecell.md \\ *Sicklecell.md FAQ: "Why is Sickle Cell \\ Anaemia only found in Black people?
}

Correspondence: Oluwatoyin Olatundun Ilesanmi, Behavioural Studies Department, College of Management Sciences, Redeemer's University, Mowe, Ogun State, Nigeria

E-mail: toytundun@yahoo.com

Key words: pathology, sickle cell disorder, implications, counseling and psychotherapy.

Dr Ilesanmi Oluwatoyin Olatundun, Clinical Psychologist, PN \& M, Trained Genetic Counselor, is concerned with taking care of people with the sickle cell disorder, to create awareness about the prevention and control of sickle cell disorder, blood group Rhesus factor, malaria control in sickle cell disease, research and raising awareness on HIV/AIDS in Nigeria and beyond, through information, psychoeducation and communication, screening and genetic counseling.

Received for publication: 11 May 2009.

Revision received: 28 December 2009.

Accepted for publication: 5 January 2010.

This work is licensed under a Creative Commons Attribution 3.0 License (by-nc 3.0).

(C) Copyright 0.0. Ilesanmi., 2010

Licensee PAGEPress, Italy

Hematology Reports 2010; 2:e2

doi:10.4081/hr.2010.e2

hemoglobin $\mathrm{S}(\mathrm{HbS})$ makes up at least half of the hemoglobin present. Globally, sickle cell disorders include sickle cell genotypes $(\mathrm{Hb}$ SS), and at least five other major hemoglobinopathies in which $\mathrm{Hb} \mathrm{S}$ is associated with abnormal hemoglobin. For example, sickle beta-thalassemia syndromes ( $\mathrm{HbS}-\beta-0$ thalassemia with variable levels of $\mathrm{Hb} \mathrm{A}), \mathrm{HbS}^{-} \beta$ Thal HbSC disorder, HbS/hereditary persistence of fetal hemoglobin (S/HPHP), HbSE syndrome, rare combinations of $\mathrm{HbS}$ with $\mathrm{HbD}$ Los Angeles, HbO Arab, G-Philadelphia, among others. SS and $\mathrm{S} \beta 0$ thalassemia have similar clinical presentation. $\mathrm{SC}$ and $\mathrm{S} S \mathrm{~S}^{+}$thalassemia have milder presentation than SS, but have an increased risk of proliferative sickle retinopathy. Risk of central nervous system (CNS) complications for patients with $\mathrm{S} \beta 0$ thalassemia and the rare SOArab, is similar to that for SS patients. For this reason, individuals with SS, S $\beta 0$, and SOArab genotypes are often grouped in clinical studies and in the term sickle cell anemia (SCA). Cerebral injury is one of the severe complications of SCA.

\section{Pathophysiological mechanisms} precipitating sickle cell disorder crisis

Current treatment and understanding of SCD require an appreciation of the complexity of its basic pathophysiology. These are the complex mechanisms by which abnormal hemoglobin produces the profound, systemic, and severe 
effects of SCD. ${ }^{10,11}$ These include the sickling process, hemoglobin cyclic polymerization, the generation of dense, dehydrated red cells, coagulation abnormalities and the interaction between sickle red cells and abnormal activated vascular endothelial cells, among others.

\section{Sickling process}

This is the pathophysiological basis of SCD. It is markedly accelerated when intracellular concentration of $\mathrm{Hb} \mathrm{S}$ is increased. Sickle cells are short lived and can interact with endothelial cells, leukocytes, platelets, and other plasma components. The sickling occurs because of a mutation in the hemoglobin gene. It begins with the substitution of valine for glutamic acid at the sixth position of the beta-globin chain. The association of heme plus 2 normal $\alpha$-globin and 2 abnormal $\beta$-globin chains forms $\mathrm{Hb} \mathrm{S}$. It normally carries oxygen but begins to form semi-solid aggregate structures once oxygen is unloaded to the tissues. These $\mathrm{Hb} \mathrm{S}$ aggregates distort RBCs and decrease the cells' flexibility. Repeated deoxygenation cycles cause permanent red-cell damage (Figure 1).

In 1940, Ham and Castle noted that sickling leads to a risk of various inflammatory complications characterized by vascular endothelium activation and increased blood cell-endothelium interactions. ${ }^{12}$ They suggested that any condition that caused a "primary increase in the plasma viscosity" would delay passage of the erythrocytes through the capillaries, producing an increase in sickling and a "vicious cycle" of venous stasis, further sickling, capillary congestion, and infarction.

Hemoglobin cyclic polymerization or erythrocyte density (see Table 1)

The polymerization of deoxy $\mathrm{Hb} \mathrm{S}$ is essential to vaso-occlusive phenomena. ${ }^{10}$ Mature erythrocytes are derived from committed erythroid progenitor cells through series of mitotic divisions and maturation phases. Erythropoietin, a humoral agent produced mainly by the kidneys, stimulates erythropoiesis by acting on committed stem cells to induce proliferation and differentiation of erythrocytes in the bone marrow. Tissue hypoxia (lack of oxygen) is the main stimulus for erythropoietin production. Nucleated red cell precursors in the bone marrow are collectively called normoblasts or erythroblasts. RBCs that have matured to the non-nucleated stage gain entry to the peripheral blood. Once the cells have lost their nuclei, they are called erythrocytes. Young erythrocytes that contain residual RNA are called reticulocytes.

In SCD, young, "sticky" erythrocytes containing $\mathrm{Hb} \mathrm{S}$ adhere to the post-capillary venule, narrowing its lumen. This decreases velocity of blood flow and increases erythrocyte transit time. Subsequently, $\mathrm{Hb} \mathrm{S}$ becomes deoxygenated as the stagnant blood unloads
Table 1. Polymerization of deoxy-Hb. ${ }^{14}$

$\begin{aligned} & \text { Sickling-unsickling } \\ & \text { anemia }\end{aligned}$
ISC
RSC
Microvascular occlusion
Tissue ischemia
Tissue damage
Pain perception

Legend: Polymer formation as a function of hemoglobin concentration for mixtures of $\mathrm{Hb} \mathrm{S} / \mathrm{Hb}$ A2 variants.

Polymerization of deoxygenated $\mathrm{Hb} \mathrm{S}$ is the primary event in the molecular pathogenesis of sickle cell disease, resulting in a distortion of the shape of the erythrocyte and a marked decrease in its deformability. These rigid cells are responsible for the vasoocclusive phenomena that are the hallmark of the disease.

more oxygen to surrounding tissues. Deoxyhemoglobin $\mathrm{S}$ is much less soluble than the oxygenated variety, and a hydrophobic interaction between $\mathrm{Hb} \mathrm{S} \beta$ chains precipitates a double stranded, rope-like polymer that causes erythrocyte sickling and rigidity. ISCs become wedged and occlude the small vessels, producing ischemia and eventually necrosis in the affected vascular territory, initiating an inflammatory response and neuropeptide release (Figure 2). These last two factors produce pain, which is a potent stimulator of the sympathetic nervous system. Classic norepinephrine-mediated tachycardia, tachypnea, and related hypertension may be noted. The high sympathetic activity also produces vasoconstriction, further decreasing distal blood flow and renewing the sickling cycle.

In 1997, Bunn noted that erythrocytes in patients with SCD are more adherent to the endothelium than in normal subjects, and the degree of adherence is associated with disease severity. ${ }^{10}$ The erythrocyte $\alpha 4 \beta 1$ integrin complex interacts with endothelial VCAM-1 and fibronectin. Additionally, erythrocyte CD36 and sulphated glycans interact with endothelial CD36. Endothelial factors VCAM-1 and fibronectin are up-regulated by infectious or inflammatory processes via tumor necrosis factor- $\alpha$; the CD36 interactions are mediated by von Willebrand factor and thrombospondin from activated platelets. These interactions explain infection as a cause of increased frequency of VPC.

The rate and extent of $\beta S$ polymer formation depends primarily on the degree of erythrocyte oxygenation, the concentration of intra-erythrocyte hemoglobin, and the concentration of hemoglobin F. ${ }^{10}$ Physical chemistry dictates that higher concentrations of solutes promote precipitation; therefore, as the erythrocyte becomes dehydrated, the high intra-erythrocyte hemoglobin concentration encourages $\beta S$ - $\beta$ S polymerization. The potassium-chloride and calcium-potassium erythrocyte ion channels are particularly important. ${ }^{10} \mathrm{Hb} \mathrm{S}$ and $\mathrm{C}$ mutations both lead to increased potassiumchloride co-transport, resulting in the formation of target cells, erythrocyte dehydration, increased intra-erythrocyte hemoglobin, and

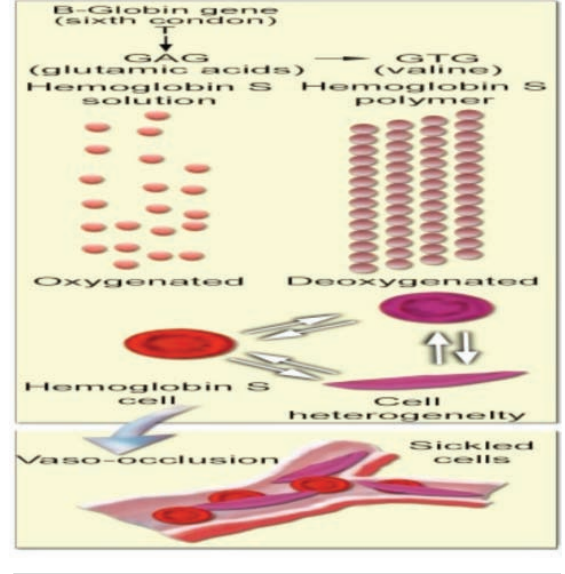

Figure 1. Molecular and cellular changes of hemoglobin S. ${ }^{12}$ Legend: $\beta 6 \mathrm{Glu} \Rightarrow$ Val. Deoxy $\mathrm{Hb} S$ polymer forms with low $\mathrm{O} 2$, Causes irreversibly sickled cells. Under a variety of circumstances, different organs are susceptible: esp. bone, spleen, and lung.

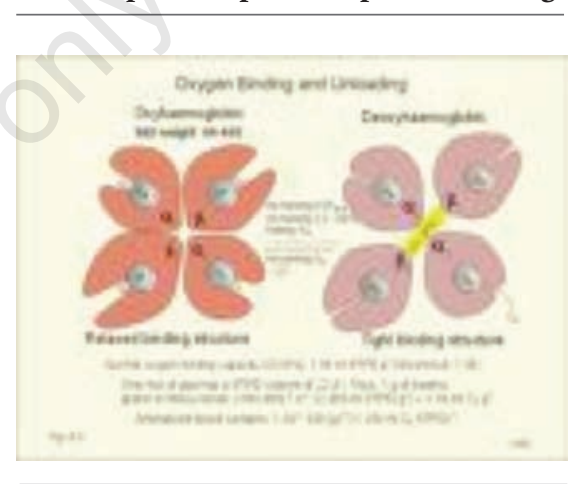

Figure 2. Oxy versus deoxyhemoglobin. ${ }^{15}$ Legend: $\alpha=$ Alpha globins; $\beta=$ Beta globins.

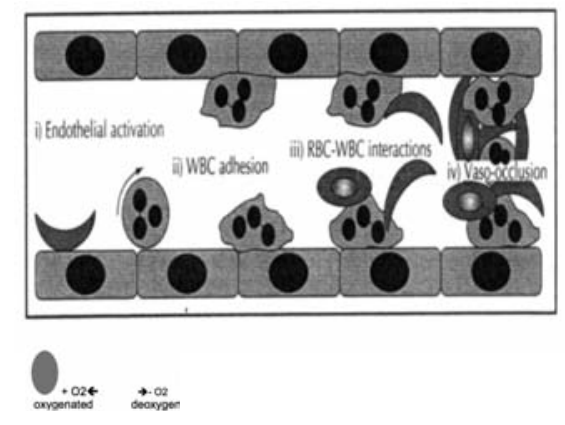

Figure 3. Red cell morphology. ${ }^{16}$ Legend: RBC: red blood cells i) Endothelial activation; ii) WBC adhesion; iii) RBC-WBC interactions; iv) vasoocclusion. Lumen obstruction results from interaction $b / w$ WBC, RBC, platelets, plasma proteins \& vascular endothelium.

promotion of $\beta S$ polymerization. The $\mathrm{Ca}^{++}$ activated $\mathrm{K}^{+}$efflux (Gardos) channel also produces dehydration/polymerization, particularly when activated by the acidotic environment in stagnant capillary beds (Figure 3 ). 
Erythrocyte maturation, survival and function

Reticulocytes are released from the bone marrow into the peripheral blood where they mature into erythrocytes, usually within 24 hours. Mature RBCs have a lifespan of 100-120 days and senescent RBCs are removed by the spleen. Three areas of RBC structure/metabolism crucial for normal erythrocyte maturation, survival and function are: i) the RBC membrane; ii) hemoglobin structure and function; and iii) cellular energy. Defects or problems associated with any of these will result in impaired RBC survival. The RBC must be flexible in order to squeeze through the capillaries of the spleen. Flexibility is a property of the membrane and the fluidity of the cell's content. Any decrease in flexibility results in a decrease in RBC deformability and a decrease in RBC survival in passage through the spleen.

The RBC membrane is a semi-permeable lipid bilayer supported by a protein cytoskeleton (contains both integral, e.g. glycophorins, and peripheral proteins). The constituents of the RBC membrane are phospholipids and cholesterol. Exchange between phospholipids in the membrane and the plasma may occur. Since the fatty acid content of the diet and the plasma are correlated, changes in the diet may have an effect on the fatty acid composition of the phospholipids in the RBC membrane which can adversely affect the flexibility of the $\mathrm{RBC}$ and may result in an $\mathrm{RBC}$ with a decreased survival time. Membrane cholesterol exists in free equilibrium with plasma cholesterol. Therefore, an increase in free plasma cholesterol results in an accumulation of cholesterol in the RBC membrane. RBCs with increased cholesterol appear distorted and the increased cholesterol results in the formation of target cells and acanthocytes. An increase in the cholesterol to phospholipid ratio results in a cell membrane that is less deformable and, therefore, the RBC has a decreased survival time.

Glycophorin is a single-pass trans-membrane integral protein. Glycophorin, which functions as cationic pumps that require ATP, helps the RBC maintains its volume and water homeostasis by controlling the intracellular concentrations of $\mathrm{Na}^{+}$and $\mathrm{K}^{+}$. ATP is also required in the $\mathrm{Ca}^{++}$pump system that prevents excessive intracellular build-up of $\mathrm{Ca}^{++}$. In ATP depleted cells, there is an intracellular build-up of $\mathrm{Na}^{+}$and $\mathrm{Ca}^{++}$and a loss of $\mathrm{K}^{+}$and water. This leads to dehydrated, rigid cells that are culled by the spleen. Any abnormality that increases membrane permeability or alters cationic transport may lead to reduced $\mathrm{RBC}$ survival.

Maintenance of $\mathrm{Hb}$ function requires active RBC metabolic pathways for ATP production. The major peripheral protein is spectrin, which is a heterodimer consisting of two antiparallel chains helically intertwined. It under-

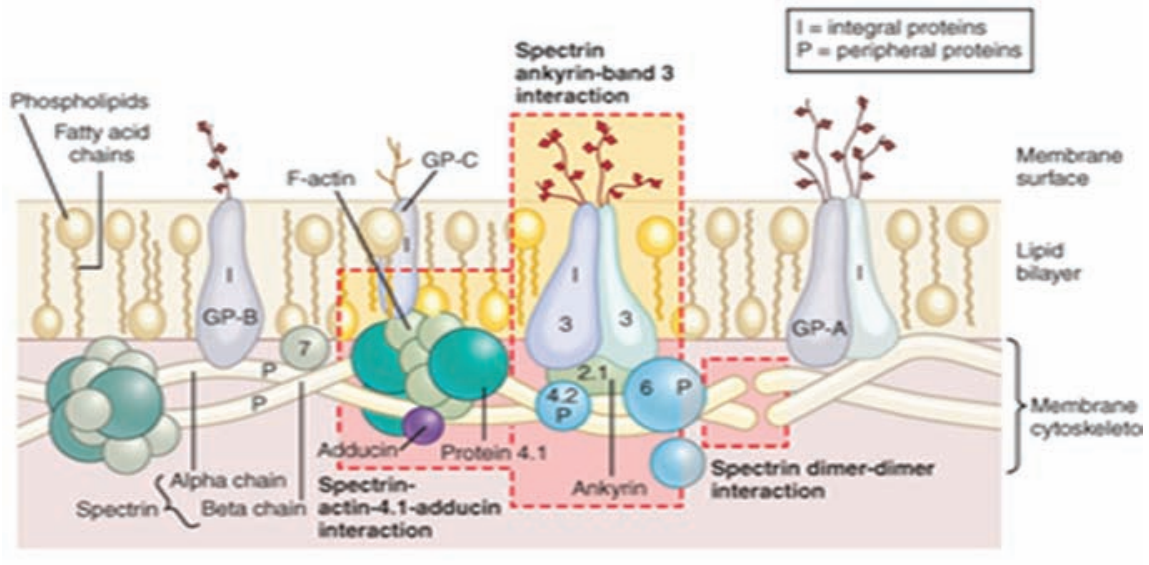

Figure 4. RBC membrane structure. ${ }^{17}$ Legend: $\mathbf{I}=$ Integral Proteins; $\mathbf{P}=$ Peripheral Proteins; hemoglobin occupies $33 \%$ of the RBC volume and $90-95 \%$ of the dry weight; $65 \%$ of the hemoglobin synthesis occurs in the nucleated stages of RBC maturation and $35 \%$ during the reticulocyte stage; normal hemoglobin consists of 4 heme groups, which contain a protoporphyrin ring plus iron, and globin, which is a tetramer of 2 pairs of polypeptide chains.

lies the membrane, which maintains the structural integrity of the cell. It interacts with other peripheral proteins such as actin and tropomyosin to form a skeleton of microfilaments on the inner surface of the membrane. It binds with various proteins on the inner surface of the cell membrane. For example band 3, a trans-membrane protein, is attached to ankyrin, which binds spectrin, a covalentlybound membrane protein called band 4.1 which binds spectrin in a complex with adducin, actin and tropomyosin. This strengthens the membrane and gives it its elastic properties. For spectrin to participate in this interaction, it must be phosphorylated by a protein kinase that requires ATP. Thus, a decrease in ATP leads to reduced phosphorylation of spectrin. Unphosphorylated spectrin can no longer bind to actin to give the membrane its elastic properties. This then leads to a loss in membrane deformability and reduced RBC survival time (Figure 4).

\section{Abnormalities of hemoglobin structure and function}

Hemoglobin is a two-way respiratory carrier, transporting oxygen from the lungs to the tissues and facilitating the return transport of carbon dioxide. In the arterial circulation, hemoglobin has a high affinity for oxygen and a low affinity for carbon dioxide, organic phosphates, and hydrogen and chloride ions. In the venous circulation, these relative affinities are reversed (Figure 5).

$\mathrm{Hb}$ occupies $33 \%$ of the RBC volume and 90 $95 \%$ of the dry weight. Sixty-five percent of the hemoglobin synthesis occurs in the nucleated stages of RBC maturation and 35\% during the reticulocyte stage. Normal $\mathrm{Hb}$ consists of 4 heme groups, which contain a protoporphyrin ring plus iron, and globin, which is a tetramer of 2 pairs of polypeptide chains. Normal $\mathrm{Hb}$

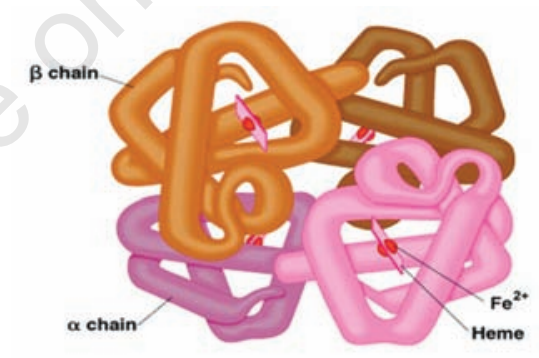

Figure 5. $\alpha=$ Alpha Chains. The $\alpha$-globin genes are on chromosome 16. $\beta=$ Beta Chains. The $\beta$-globin genes are on chromosome 11. $\mathrm{Fe}^{2+}=$ Ferrous indicates a bivalent iron compound $(+2$ oxidation state), as opposed to ferric, which indicates a trivalent iron compound $(+3$ oxidation state). Heme $=$ is a prosthetic group that consists of an iron atom contained in the center of a large heterocyclic organic ring called a porphyrin. Not all porphyrins contain iron, but a substantial fraction of porphyrincontaining metalloproteins have heme as their prosthetic group; these are known as hemoproteins.

production is dependent upon three processes: adequate iron delivery and supply, adequate synthesis of protoporphyrins and adequate globin synthesis. Iron is delivered to the RBC precursor by transferrin. It goes to the mitochondria where it is inserted into protoporphyrin to form heme. Synthesis of protoporphyrin begins in the mitochondria where glycine plus succinyl CoA results in delta aminolevulenic acid ( $\delta$ ALA).

Abnormalities of hemoglobins were first described in the peripheral blood of an anemic patient from the West Indies by the Chicago physician Robert Herrick. ${ }^{13}$ In 1957, Ingram demonstrated that sickle cell anemia was caused by the replacement of one of the 287 
amino acid residues in the half molecule of $\mathrm{Hb}^{14}$ This finding improved understanding of the disorder at the molecular level, since for the first time a point mutation in a structural gene was shown to cause the substitution of one amino acid in the protein controlled by that gene. Furthermore, in 1954, Allison indicated that the accumulation of the sickle cell gene in malarial regions of the world is an illustration of Darwin's theory of evolution by natural selection. ${ }^{15}$ To date, well over 200 variants and abnormal hemoglobins have been described.

Hemoglobin $\mathrm{S}(\mathrm{Hb} \mathrm{S})$ results from a single base-pair mutation in the gene for the betaglobin chain of adult hemoglobin. An adeninethymine substitution in the sixth codon replaces glutamic acid with valine in the sixth amino acid position of the beta-globin chain. ${ }^{10,16}$ This substitution yields electrophoretically distinct $\mathrm{Hb} .{ }^{17}$ In the deoxygenated form of $\mathrm{Hb} \mathrm{S}$, the beta- 6 valine becomes buried in a hydrophobic pocket on an adjacent betaglobin chain, joining the molecules together to form insoluble polymers. ${ }^{10}$ In sufficient concentration, these insoluble polymers give rise to the classical sickle morphology. This process causes severe damage to the red cell membrane. Sickled red cells may then aggregate and go on to cause microvascular obstruction. Also, these abnormal red cells adhere to endothelial cells ${ }^{18}$ and can interact with various cytokines. ${ }^{19}$

\section{Endothelial dysfunction}

The vessel wall endothelium undoubtedly plays a role in the vascular pathobiology of Sickle Cell Disorder. In individuals with SCD, a state of endothelial dysfunction is observed. Endothelial cells (ECs) line the inner surface of blood and lymphatic vessels, and play important roles in the development and remodeling of vasculature, maintenance of vascular tone, blood fluidity, coagulation, nutrient exchange, and organ development. Endothelial dysfunction is characterized by a shift of the actions of the endothelium toward reduced vasodilation, a proinflammatory state, and prothrombic properties. It is associated with most forms of cardiovascular disease, such as hypertension, coronary artery disease, chronic heart failure, peripheral artery disease, diabetes, and chronic renal failure. Mechanisms that participate in the reduced vasodilatory responses in endothelial dysfunction include reduced nitric oxide generation, oxidative excess, and reduced production of hyperpolarizing factor. Upregulation of adhesion molecules, generation of chemokines such as macrophage chemoattractant peptide-1, and production of plasminogen activator inhibitor-1 participate in the inflammatory response and contribute to a prothrombic state. Vasoactive peptides such as angiotensin II and endothelin-1, the accumulation of asymmetric dimethylarginine, an endogenous nitric oxide inhibitor, hypercholesterolemia, hyperhomocysteinemia, altered insulin signaling, and hyperglycemia can contribute to these different mechanisms. Detachment and apoptosis of endothelial cells (anoikis) are associated phenomena.

Depletion of nitric oxide in sickle cell anemia

Nitric oxide (NO) is an uncharged free radical that is produced during the enzymatic conversion of L-arginine to L-citrulline by members of the NOS family of proteins in endothelial cells. ${ }^{20}$ Three members of the family have been identified: endothelial NOS (eNOS or NOS3), neuronal NOS (nNOS or NOS1) and inducible NOS (iNOS or NOS2), with eNOS and nNOS both functioning in a calciumdependent and independent fashion, and iNOS functioning in a calcium independent fashion. ${ }^{20}$ The bioavailability of nitric oxide (NO) within the vascular wall is limited by superoxide anions $\left(02^{-}\right)$in sickle cell disease. The amount of free, bioactive NO in the vascular wall is determined by the activity of the endothelial NO synthase (eNOS) and by NOscavenging mechanisms, such as the reaction of NO with superoxide anions $\left(02^{-}\right){ }^{21}$ Numerous studies have demonstrated that indeed the local $02^{-}$concentration is the main limiting factor for the availability of bioactive NO in healthy and diseased vessels. ${ }^{21}$

Nitric oxide (NO) was identified originally as the endothelium derived relaxation factor that mediates vasodilation in a soluble guanylate cyclase (sGC) in a dependent manner in smooth muscle ${ }^{22}$ to counter the processes induced by hypoxia. Because NO readily diffuses through cell membranes and can bind with high affinity to heme-containing proteins (e.g. sGC) or nitrosylate proteins, it has been reported to exhibit complex pleiotropic effects and is central to many aspects of physiology and pathology.

Nitric oxide is a regulator of smooth muscle tone and platelet activation, and reductions in nitric oxide plasma levels lead to smooth muscle dystonias, including hypertension, gastrointestinal contractions, and erectile dysfunction, as well as clot formation (Figure 6).

Nitric oxide is a critical regulator of vasodilation and vascular homeostasis. Since the reaction of nitric oxide with the vast amounts of intravascular oxyhemoglobin $(16 \mathrm{~g} / \mathrm{dL})$ is fast $\left(107 \mathrm{M}^{-1} \mathrm{~s}^{-1}\right)$ and irreversible, it would be expected that nitric oxide produced by endothelium would be immediately scavenged by hemoglobin and would, therefore, be incapable of paracrine diffusion from endothelium to vascular smooth muscle. ${ }^{23,24}$ However, the ability of hemoglobin to react with nitric oxide produced by endothelium is limited by compartmentalization of $\mathrm{Hb}$ inside the erythrocyte. ${ }^{25-27}$ Thus, the evolution of the erythrocyte

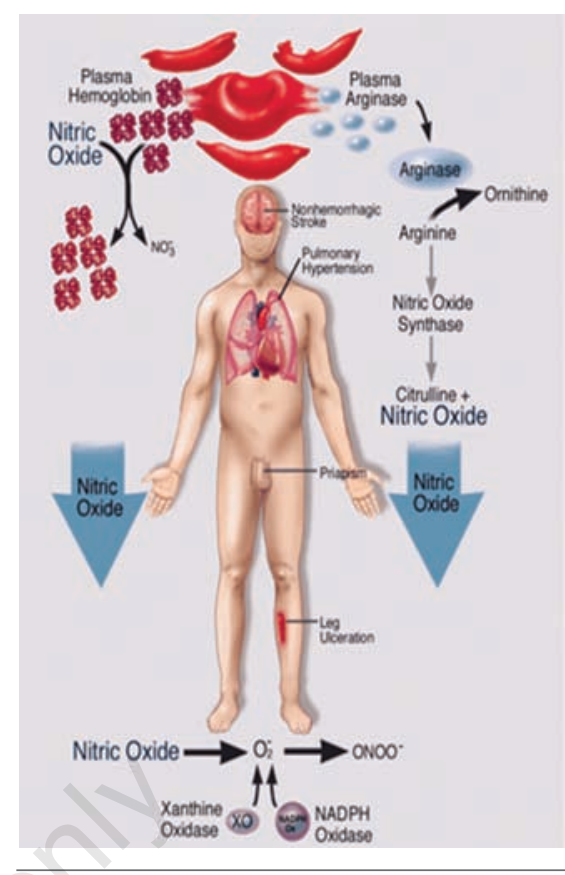

Figure 6. Depletion of nitric oxide in sickle cell anemia. ${ }^{29}$ Legend: Sickle cell disease Hemolysis Arginine $\downarrow$ NO $\downarrow$. During intravascular hemolysis, hemoglobin is released into the plasma where it is normally cleared by the hemoglobin scavengers haptoglobin, CD163, and hemopexin. Haptoglobin-hemoglobin complexes bind to CD163 on the surface of macrophages/ monocytes initiating endocytosis and degradation of the complex. Hemoglobin also releases ferric heme on oxidation, which is bound by hemopexin and degraded by hepatocytes in the liver. Excessive hemolysis saturates and depletes these hemoglobin removal systems and leads to a build-up of hemoglobin and heme in the plasma. Plasma hemoglobin and heme mediate direct proinflammatory, proliferative, and pro-oxidant effects on vessel endothelial cells. NO is normally generated from L-arginine in vessel endothelial cells by the enzyme nitric oxide synthase (NOS). NO maintains smooth muscle relaxation and inhibits platelet activation and aggregation, thereby regulating vessel tone and promoting organ system homeostasis. During intravascular hemolysis, NO availability can be severely limited by its reaction with oxyhemoglobin (NO scavenging) and by the breakdown of the substrate for NO synthesis, L-arginine, by the red cell enzyme arginase, despite elevated levels of NOS (decreased NO synthesis). NO depletion results in decreased activation of guanylate cyclase, an enzyme required for the generation of cyclic guanine monophosphate (cGMP). Decreased cGMP levels disrupt regulation of smooth muscle tone resulting in dystonias, including systemic and pulmonary hypertension, erectile dysfunction, dysphagia, and abdominal pain. Decreased cGMP levels through the depletion of NO can also lead to platelet activation and aggregation, promoting clot formation. GTP indicates guanosine 5'triphosphate. (Modified from JAMA 2009). 
may be considered a mechanism of reducing toxicity while ensuring separation of the critical respiratory transport machinery needed for efficient oxygen delivery from the endothelium. Moreover, multiple systems have evolved to control the level of cell-free $\mathrm{Hb}$ in the plasma during normal physiological hemolysis, presumably to curtail the deleterious effects of plasma $\mathrm{Hb}$ on nitric oxide bioavailability and endothelial function.

\section{Inflammatory mediators}

Interaction of inflammatory mediators or nociceptive pain in SCD involves four major pathophysiological processes that explain the pain experience (Figure 7): transduction, transmission, modulation, and perception..$^{28-33}$ Transduction is the process through which noxious inflammatory mediators (collectively referred to as inflammatory soup, including prostaglandins, histamines, bradykinin, $\mathrm{H}^{+}$, $\mathrm{K}^{+}$, cytokines, serotonin, substance $\mathrm{P}$, leukotrienes, and others) are generated by tissue damage. These inflammatory mediators activate nociceptors by converting chemical or mechanical energy to an electrochemical impulse in the primary afferent nerve fibers. Interleukin-1 (IL-1) is an endogenous pyrogen and also activates the cyclo-oxygenase gene, which leads to synthesis of prostaglandins $E_{2}$ and $\mathrm{I}_{2}$. Bradykinin, potassium, hydrogen ions, and serotonin activate nociceptive afferent nerve fibers and evoke a pain response. Prostaglandins, leukotrienes, nerve growth factor, and bradykinin sensitize peripheral nerve endings and facilitate the transmission of painful stimuli that reach the cerebral cortex via the spinal cord and the thalamus. Activated nociceptors release stored substance $P$ in peripheral nerves and in the spinal cord, which itself facilitates the transmission of painful stimuli. Bradykinin and substance $P$ also cause vasodilatation with extravasation of fluids that can lead to local swelling and tenderness. Prostaglandins increase the effective renal blood flow and effective renal plasma flow in children and young adults. ${ }^{34}$ Prostaglandins $\mathrm{PGE}_{2}$ and $\mathrm{PGI}_{2}$ infused directly into the renal arteries of dogs increase renal blood flow and provoke diuresis, natriuresis, and kaliuresis. ${ }^{34}$ The painful stimulus is then transmitted along $A-\delta$ and $C$ peripheral nerve fibers to the dorsal horn of the spinal cord, where it may be enhanced or suppressed by several receptors. Most important among these is the N-methyl-D-aspartate (NMDA) receptor at the dorsal horn that facilitates the transmission of the painful stimulus once activated. From there, the stimulus crosses to the contralateral side and ascends along the spinothalamic tracts to the thalamus, which is a relay station, and interacts with the hypothalamus, reticular formation (associated with awareness and behavior), and the limbic sys- tem, including the amygdala, the hippocampus (associated with memory), and nucleus accumbens. The limbic system also contains the brain's reward/pleasure circuit, as will be discussed below. Modulation refers to descending fibers from the midbrain to the dorsal horn that can inhibit the transmission of the painful stimuli via endogenous endorphins, serotonin, and norepinephrine. Taken together, communications and interactions among the thalamus, hypothalamus, the reticular formation, the limbic system, and the descending modulation system enhance or ameliorate the intensity of pain perceived at the level of the cerebral cortex (Figure 7).

Although sickle cell pain is primarily a nociceptive type of pain due to tissue damage, it may also have a neuropathic component ${ }^{35}$ characterized by sensations of burning, tingling, shooting numbness, and lancinating pain (i.e. stabbing pain, from lancinate, to stab, from the Latin lancināre, lancināt-, to lacerate). These symptoms may occur in the presence or absence of obvious central or peripheral nerve injury. The mechanism of neuropathic pain presumably involves aberrant somato-sensory processing in the central or peripheral nervous system. Mental nerve neuropathy, trigeminal neuralgia, acute proximal median mononeuropathy, entrapment neuropathy, and acute demyelinating polyneuropathy have been described in SCD.,36 A thorough history and physical examination help determine whether sickle cell pain is associated with a neuropathic component that can be managed using special adjuvants, including anticonvulsants.

\section{The pathology of sickle cell disorder symptoms}

Essentially, the multi-systemic complications in SCD include a multitude of diagnostic considerations classified as molecular pathology, biochemical pathology, cellular pathology, vascular pathology and clinical pathology.

\section{Molecular pathology}

In molecular terms, sickle cell disease (SCD) is caused by a single base mutation, producing a single amino acid substitution at position 6 of the $\beta$ chain of $\mathrm{Hb}$, thus forming $\mathrm{HbS}$ rather than the normal HbA. That is, SCD is a group of chronic inherited disorders of $\mathrm{Hb}$ in which the affected person inherits two mutant globin genes from both parents; one of these genes is always the sickle mutation. That is a point mutation (GAG $\rightarrow$ GTG) in the $\beta$-globin gene $(H B B)$, a subunit of adult hemoglobin A ( $\mathrm{HbA})$, results in the substitution of valine for glutamic acid at the sixth amino acid of the $\beta$-globin chain (Glu6Val), which produces a $\mathrm{Hb}$ tetramer $(\alpha 2 / \beta \mathrm{S} 2)$ that is poorly soluble when deoxygenated. ${ }^{10}$ This mutation results in the abnormal sickle hemoglobin (HbS), when deoxygenated. This hemoglobin

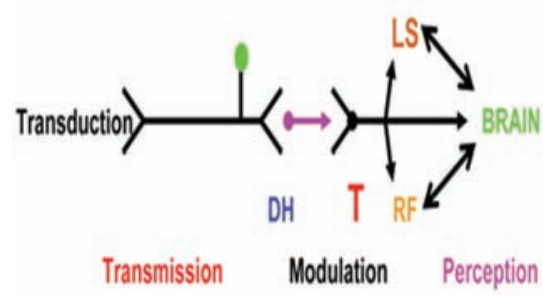

Figure 7. Ballas figure on molecular mechanisms of pain. ${ }^{35}$

(HbS) presents physical and chemical abnormalities and a tendency to polymerization under certain circumstances, damaging the sickle erythrocyte. SCA is due to homozygosity for the abnormal hemoglobin, hemoglobin S. The presence of $\mathrm{HbS}$ associated with other hereditary variants of hemoglobin such as hemoglobin $\mathrm{C}, \mathrm{D}$ and $\mathrm{S} / \mathrm{S} \beta 0$ thalassemia, among others, characterizes sickle cell disease. ${ }^{37-39}$

\section{Biochemical pathology}

The biochemical pathology of SCD involves detoxication, GSH, oxidative stress and inflammation. The first three are interrelated.

Detoxication is the process of preventing toxic entities from entering the body in the first place. It refers to the reduction of the toxic properties of a substance and treatment designed to assist in recovery from the toxic effects of a drug. It begins with the participation of increased oxidative damage in SCD. Hb $\mathrm{S}$ is more unstable than $\mathrm{Hb} \mathrm{A}$, contributing to increased generation of free radicals, ${ }^{40}$ levels of both total and reduced glutathione (GSH) are low ${ }^{41}$ the pentose phosphate pathway is impaired ${ }^{42}$ and oxidative damage is present in both proteins and lipids. ${ }^{41}$ Furthermore, in red cells from human and other species, reduction in GSH stimulates the $\mathrm{KCl}$ cotransporter (probably KCC1). ${ }^{43,44}$ This is important because $\mathrm{KCCl}$, in high $\mathrm{K}^{+}$cells, mediates increased $\mathrm{KCl}$ e ux and promotes cell dehydration. Low GSH may account partially for the high activity of $\mathrm{KCC1}$ in $\mathrm{Hb} \mathrm{S}$ cells. ${ }^{45}$ Increased oxidative stress in $\mathrm{Hb} \mathrm{S}$ cells, causing membrane damage, increased cell rigidity, altered cation permeability and cell dehydration, will all contribute to the chronic hemolysis and acute vaso-occlusive events of SCD. The oxygenation status of the red cell has other important consequences.

The extent to which a cell is able to withstand the potentially damaging effects of oxidative stress is determined by the balance between the rate at which oxidant species are generated and the capacity of metabolic processes to produce antioxidants. Erythrocyte glutathione depletion has been linked to hemolysis and oxidative stress. The glutathione (GSH) system is a major component of overall antioxidant defenses ${ }^{46}$ through preservation of intracellular nicotinamide adenine dinucleotide phosphate (NADPH) levels, 
required for glutathione recycling. GSH is synthesized de novo within all cells from glutamate, cysteine and glycine in a series of reactions catalyzed by glutamate cysteine ligase (also known as -glutamylcysteine synthetase, EC 6.3.2.2) and -L-glutamyl-L-cysteine:glycine ligase (also known as glutathione synthetase, EC 6.3.2.3). Glutamate cysteine ligase catalyzes the synthesis of the intermediate -L-glutamyl-L-cysteine from glutamate and cysteine, the rate-limiting step in GSH synthesis.

The antioxidant defense systems include a complex of interrelated functions, each of which tends to buffer the effects of the others. There is abundant evidence that the GSH concentration in erythrocytes of individuals with SCD is low and they also have increased oxidative stress. ${ }^{47}$ It has been proposed that oxidative damage of the membrane and ionic channels of the SCD erythrocyte alters its polymerization and depolymerization kinetics resulting in the formation of irreversibly sickled cells and microvascular occlusion. ${ }^{48-50}$ In 1998, Gibson et al. noted that an increase in intracellular concentrations of GSH inhibits the formation of dense cells and irreversibly sickled cells in vitro by maintaining the sulfhydryl groups of F-actin, a membrane structural protein in the reduced form. ${ }^{49}$

Notwithstanding, there are two obvious general kinetic mechanisms for the decreased intracellular GSH concentration, namely suppressed synthesis and/or increased consumption relative to synthetic capacity. In SCD there is indirect evidence for protein and energy deficiencies relative to metabolic demand. ${ }^{51}$ Additionally, in vivo kinetic experiments in normal adults have shown that GSH turnover is suppressed by diets deficient in sulfur amino acids ${ }^{52}$ and by diets with marginal amounts of protein. ${ }^{53}$

Acute inflammation is characterized by marked vascular changes, including vasodilatation, increased permeability, and the slowing of blood flow, which are induced by the actions of various inflammatory mediators. Vasodilatation occurs first at the arteriole level, progressing to the capillary level, and brings about a net increase in the amount of blood present, causing the redness and heat of inflammation. Increased permeability of the vessels results in the movement of plasma into the tissues, with resultant stasis due to the increase in the concentration of the cells within blood; a condition characterized by enlarged vessels packed with cells. Stasis allows leukocytes to marginate (move) along the endothelium; a process critical to their recruitment into the tissues. Normal flowing blood prevents this as the shearing force along the periphery of the vessels moves cells in the blood into the middle of the vessel.

\section{Cellular pathology}

This refers to the platelets and coagulation
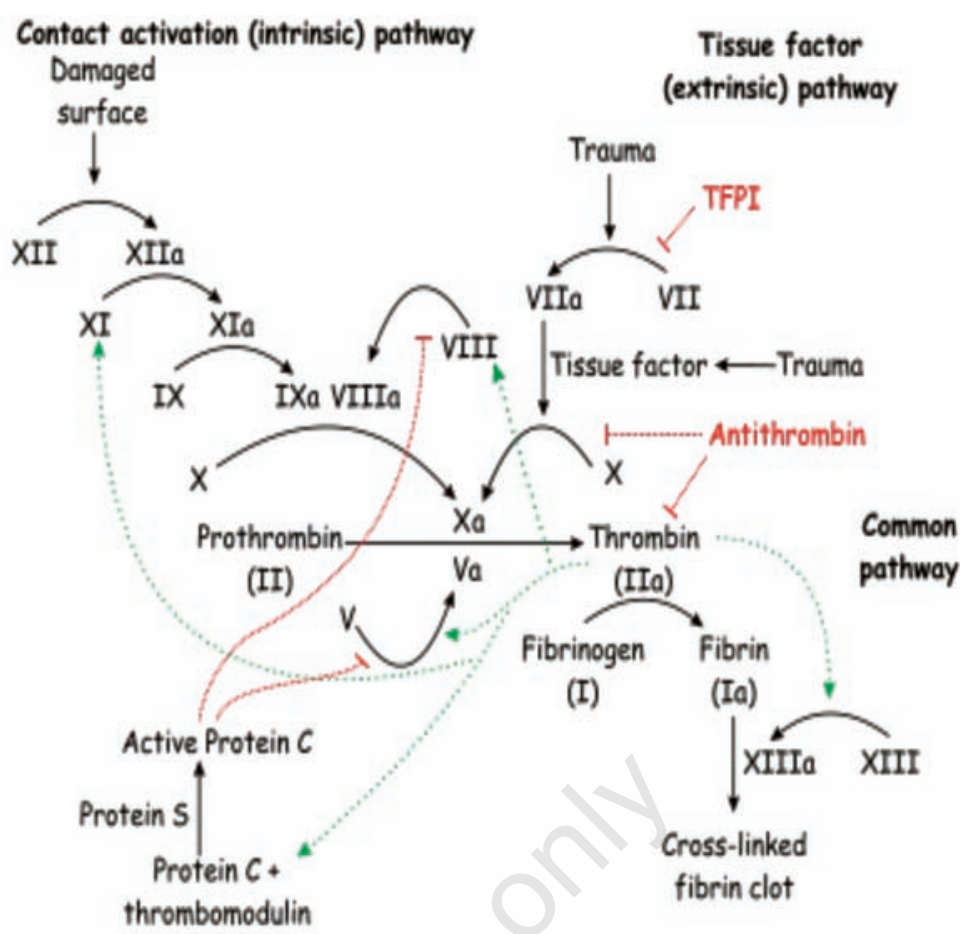

Figure 8. The Coagulation Cascade. ${ }^{72}$ Legend: this is the physiological coagulation cascade used to describe a very complex step-by-step process that occurs in the body (in vivo) when a blood vessel is injured. In the cascade, solid arrows indicate activation of a coagulation factor by the factor above it in the cascade, dotted arrows indicate activation of factors V, VIII, XI and XIII by thrombin. The intrinsic cascade (which has less in vivo significance in normal physiological circumstances than the extrinsic cascade) is initiated when contact is made between blood and exposed negatively charged surfaces. The extrinsic pathway is initiated upon vascular injury which leads to exposure of tissue factor, TF (also identified as factor III), a subendothelial cell-surface glycoprotein that binds phospholipid. The green dotted arrow represents a point of cross-over between the extrinsic and intrinsic pathways. The two pathways converge at the activation of factor $\mathrm{X}$ to $\mathrm{Xa}$. Factor $\mathrm{Xa}$ has a role in the further activation of factor VII to VIIa as depicted by the green arrow. Active factor Xa hydrolyzes and activates prothrombin to thrombin. Thrombin can then activate factors XI, VIII and V furthering the cascade. Ultimately the role of thrombin is to convert fribrinogen to fibrin and to activate factor XIII to XIIIa. Factor XIIIa (also termed transglutaminase) cross-links fibrin polymers solidifying the clot. HMWK = high molecular weight kininogen. $\mathrm{PK}=$ prekallikrein. $\mathrm{PL}=$ phospholipid.

factors. Platelets (also called thrombocytes) are tiny oval-shaped cells made in the bone marrow. They help in the clotting process. When a blood vessel breaks, platelets gather in the area and help seal off the leak. Platelets only survive about nine days in the bloodstream and are constantly being replaced by new cells. Important proteins called coagulation factors are critical to the clotting process. Although platelets alone can plug small blood vessel leaks and temporarily stop or slow bleeding, the action of coagulation factors is needed to produce a strong, stable clot. Platelets and clotting factors work together to form solid lumps that seal leaks, wounds, cuts, and scratches, and to prevent internal bleeding and bleeding on the body surfaces. When large blood vessels are severed, the body may not be able to repair itself through clotting alone. In these cases, dressings or stitches are used to help control bleeding. SCD is often referred to as a hypercoagulable state ${ }^{54}$ because patients manifest increased thrombin and fibrin gener- ation, ${ }^{55-57}$ increased tissue factor procoagulant activity, ${ }^{58}$ and increased platelet activation $^{56,57,59}$ even when they are in a non-crisis, steady state. Furthermore, thrombosis may contribute to the pathogenesis of several SCDrelated complications. For example, stroke, caused by large vessel obstruction with superimposed thrombosis, often occurs in SCD patients. ${ }^{52}$ Both pulmonary embolism and pregnancy-related venous thromboembolism appear to occur more commonly in SCD patients than in appropriate control patients. ${ }^{60,61}$ The coagulation system is in a state of activation in "steady state" sickle disorders as well as during painful crisis. It involves both a cellular (platelet) and a protein (coagulation factor) component. Coagulation begins almost instantly after an injury to the blood vessel has damaged the endothelium (lining of the vessel). This releases phospholipid components called tissue factor and fibrinogen that initiate a chain reaction. Platelets immediately form a plug at the site of injury; 
this is called primary hemostasis. Secondary hemostasis occurs simultaneously. ${ }^{62}$ Proteins in the blood plasma, called coagulation factors or clotting factors, respond in a complex cascade to form fibrin strands, which strengthen the platelet plug (Figure 8).

\section{Vascular pathology}

The vascular system is a complex network of vessels connecting the heart with diverse organs and tissues to maintain their homeostasis in response to physiological and pathological changes. The vascular system is locally specialized to accommodate widely varying blood flow and pressure, and the distinct needs of individual tissues.

$\mathrm{RBC}$ destruction is normally the result of senescence. Each day about $1 \%$ of the RBCs are removed and replaced. $\mathrm{RBC}$ aging is characterized by decreased glycolytic enzyme activity which leads to decreased energy production and subsequent loss of deformability and membrane integrity. Ninety percent of aged $\mathrm{RBC}$ destruction is extravascular and occurs mainly in the phagocytic cells of the spleen, with a small amount occurring in the liver and bone marrow. Extravascular hemolysis occurs in three situations: the red cells appear damaged, the red cells are less deformable, and the red cells are the targets of an immune reaction. Examples of extravascular hemolysis include: i) sickle cell disease; during a crisis, hypoxia results in gelling of the $\mathrm{Hb} \mathrm{S}$, the red cells become less deformable, and phagocytosis within mononuclear cells in the spleen results in extravascular hemolysis, and ii) hereditary spherocytosis; the abnormal cytoskeleton reduces the deformability of the red cells. The clinical features of extravascular hemolysis include: jaundice, anemia and no hemoglobinuria. The serum haptoglobin is reduced because small amounts of free hemoglobin do enter the blood. Haptoglobin is an alpha-2-globulin. The function of haptoglobin is to bind free hemoglobin in the blood, with a capacity of up to 1.4 grams per liter. The haptoglobin-hemoglobin complexes are removed by the reticuloendothelial system, resulting in a reduction in the concentration of haptoglobin. It is only when the binding capacity is rapidly exceeded - in acute hemolysis - that hemoglobin appears in urine. Haptoglobin is an acute phase protein, rising in concentration during acute inflammation (Figure 9).

About $5-10 \%$ of RBC destruction is intravascular, occurring in the lumen of the blood vessels. Intravascular hemolysis is less common, requiring mechanical (prosthetic heart valves and the microangiopathic hemolysis associated with disseminated intravascular coagulation and other processes) or immune (antibody-mediated, e.g. transfusion reaction and complement-mediated, e.g. paroxysmal nocturnal hemoglobinuria) disruption of the red cells

\section{NORMAL EXTRAVASCULAR HEMOLYSIS}

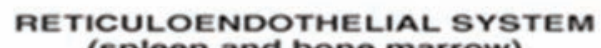

(spleen and bone marrow)

NORMAL

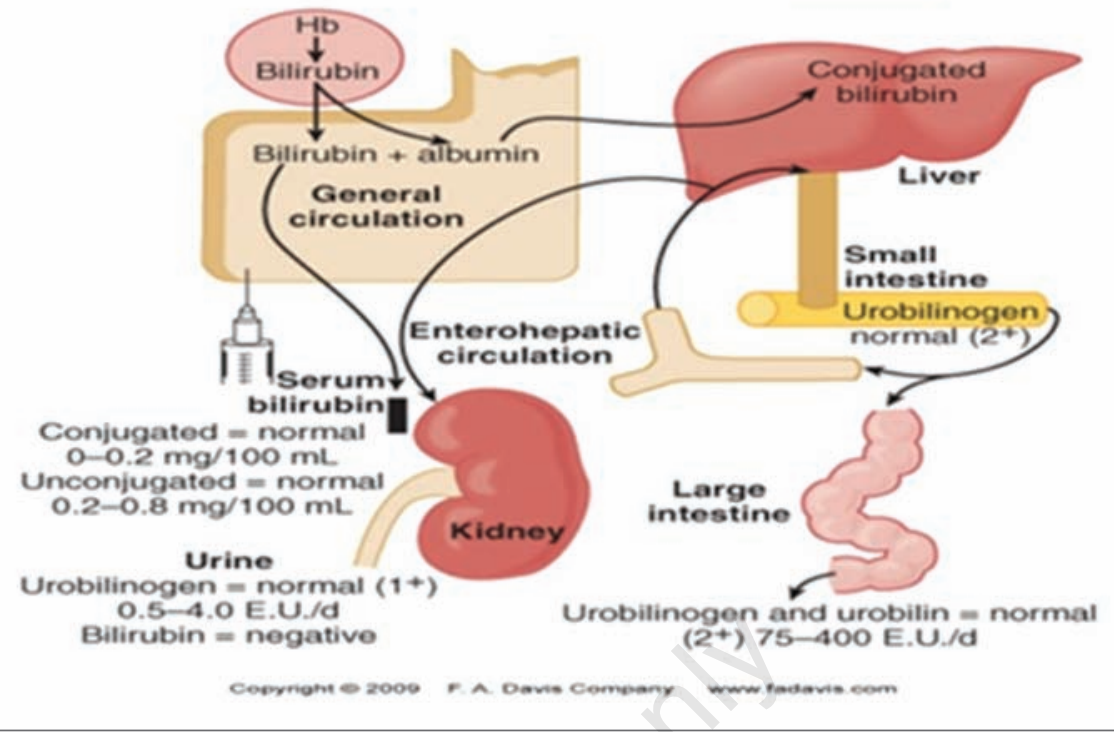

Figure 9. Extravascular destruction of RBCs. ${ }^{73}$ Legend: Extravascular hemolysis occurs when damaged or abnormal RBCs are cleared from the circulation by cells of the spleen, liver, and bone marrow similar to the process by which senescent RBCs are removed. The spleen usually contributes to hemolysis by destroying mildly abnormal RBCs or cells coated with warm antibodies. An enlarged spleen may sequester even normal RBCs. Severely abnormal RBCs or RBCs coated with cold antibodies or complement (C3) are destroyed within the circulation and in the liver, which (because of its large blood flow) can remove damaged cells efficiently.

within the vascular system.

Heart valve replacements may be xenografts such as pig valves, cadaveric homografts or artificial valves. Bioprostheses are less durable than artificial valves but the patient does not need permanent anticoagulation. Pig valves are, therefore, used in the elderly and in women who want to bear children. Two common artificial valves are the tilting disc and the ball-and-cage valve. Each of these valves carries the risk of infective endocarditis, leakage and thromboembolism. Patients with these valves require antibiotic prophylaxis when undergoing any invasive procedures. Replacement valves cause more trauma to platelets and red cells compared to the human valves they replace. This may be sufficient to cause thrombocytopenia and/or a hemolytic anemia.

Microangiopathic hemolytic anemia is an intravascular hemolysis caused by mechanical obstruction or narrowing of the microvasculature. Typically, the blood film shows fragmented red blood cells.

Transfusion of blood and blood products may be indicated in a variety of situations such as acute blood loss, correction of anemia, prophylactically before surgery or transfusion of the newborn. The specific situation will dictate the most appropriate blood product. Ideally, the patient's blood group and rhesus status should be known, and blood should be cross-matched with the proposed donor blood. Otherwise, uni- versal donor blood (group 0 negative) is used.

Paroxysmal nocturnal hemoglobinuria is an acquired clonal, benign, hematopoietic stem cell disorder which results in the formation of defective red cells, white cells and platelets. It is characterized by intravascular hemolysis and frequent venous thrombosis or bleeding. It is caused by a mutation in an X-linked gene involved in the formation of membrane phosphatidyl inositol anchors. The membranes of these cells are deficient in those proteins normally anchored to the cell through a phosphatidyl inositol linkage, including complement deactivating factors. $\mathrm{PNH}$ is a very rare disorder and should be suspected in confusing cases of hemolytic anemia. There is a median survival of ten years (Figure 10).

The vascular pathology of SCD is influenced by many factors, including adhesiveness of red and white blood cells to endothelium, increased coagulation, and homeostatic perturbation. The vascular endothelium is central to disease pathogenesis because it displays adhesion molecules for blood cells, balances procoagulant and anticoagulant properties of the vessel wall, and regulates vascular homeostasis by synthesizing vasoconstricting and vasodilating substances. The occurrence of intermittent vascular occlusion in SCD leads to reperfusion injury associated with granulocyte accumulation and enhanced production of reactive oxygen species. The participation of nitric oxide (NO) in oxidative reactions caus- 
es a reduction in NO bioavailability and contributes to vascular dysfunction in SCD. Therapeutic strategies designed to counteract endothelial, inflammatory, and oxidative abnormalities may reduce the frequency of hospitalization and blood transfusion, the incidence of pain, and the occurrence of acute chest syndrome and pulmonary hypertension in patients with SCD.

\section{Clinical pathology}

Clinical pathology of SCD includes: 1) painless crises or chronic hemolytic anemia, chronic intravascular hemolytic anemia and acute episodes of severe anemia, transient red cell aplasia (parvovirus B19), acute splenic sequestration, acute hemolysis ("hyperhemolysis"); 2) painful crises or vasoocclusion: i) microvascular occlusion, clinically silent, and ii) macrovascular occlusion, acute ischemic/ infarctive damage, pain episodes, stroke, priapism, acute chest syndrome, renal papillary necrosis and splenic infarction (there are several inter-related factors that impact on vasoocclusion in SCD, including RBC density, $\mathrm{RBC}$ rigidity, membrane anomalies, blood viscosity and endothelial cell adhesion. These aspects of vasoocclusion are discussed under the pathophysiology of SCD); and iii) chronic organ damage: splenic dysfunction, high risk of bacterial infection and progressive dysfunction of lungs (oxyhemoglobin desaturation, pulmonary hypertension, kidneys) proteinuria, renal failure, gallbladder-gallstones, eyes-proliferative retinopathy, joints-osteonecrosis, arthritis, heart-CHF.

\section{Painless crises}

Painless SCD crises or hemolytic anemia may be related to repeat cycles of sickling and unsickling, which interact to produce irreversible red cell membrane changes, red cell dehydration, and erythrocyte destruction. The painless SCD crises are hyperhemolysis, intravascular hemolysis, sequestration, aplastic, megaloblastic (folate deficiency), papillary necrosis (kidneys) and others.

Hyperhemolysis: hemolysis is the premature destruction of RBCs due to intrinsic inherited defects in the RBCs or because of acquired intravascular abnormalities. Hyperhemolysis is a rare life threatening complication of red cells occurring in multiple transfusions seen in $4 \%$ of pediatric and $1 \%$ of adult patients with thalassemia, myelofibrosis, and anemia of chronic sickle cell disease. ${ }^{64}$ Two forms of hyperhemolysis are acute or intravascular hemolysis (which usually presents within seven days of a transfusion) and delayed or extravascular hemolysis. Intravascular hemolysis and chronic anemia is an acute accelerated drop in hemoglobin level. Patients have symptoms of fever, hemolysis and hemoglobinuria. However, serological findings are usually negative (direct antiglobulin test/DAT and red

\section{INTRAVASCULAR HEMOLYSIS}

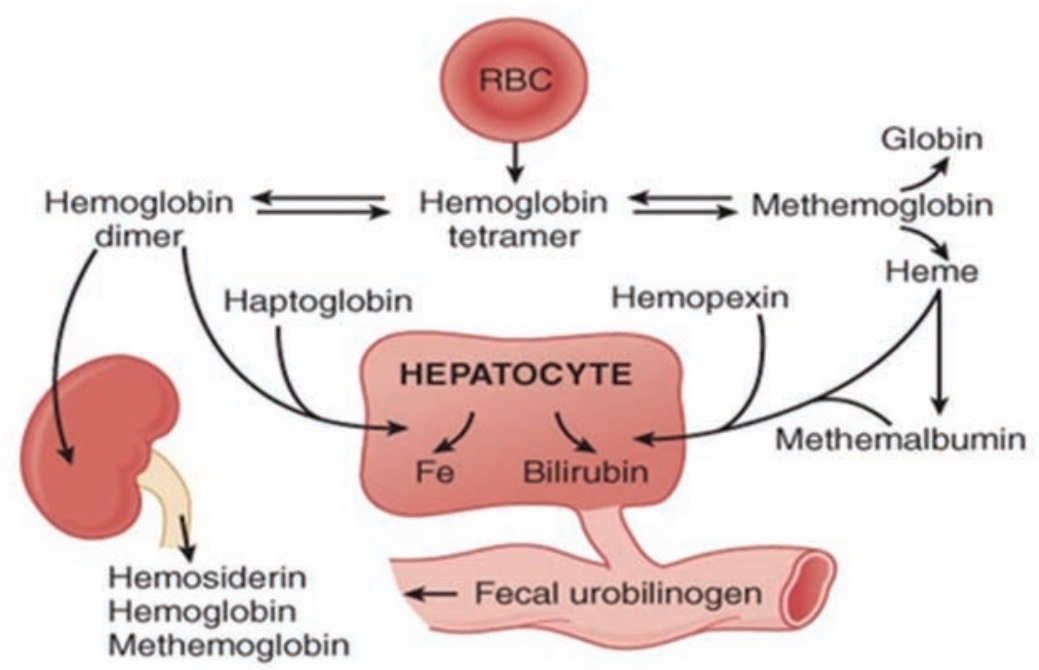

Copyright o 2000 F.A. Davis Company wnef fadavis.com

Figure 10. Intravascular destruction of RBCs. ${ }^{74}$ Intravascular hemolysis usually occurs when the cell membrane has been severely damaged by any of a number of different mechanisms, including autoimmune phenomena, direct trauma (e.g., march hemoglobinuria), shear stress (e.g., defective mechanical heart valves), and toxins (e.g., clostridial toxins, venomous snake bite). It results in hemoglobinemia when the amount of $\mathrm{Hb}$ released into plasma exceeds the Hb-binding capacity of the plasma-binding protein haptoglobin, a globulin normally present in concentrations of about $1.0 \mathrm{~g} / \mathrm{L}$ in plasma. With hemoglobinemia, unbound $\mathrm{Hb}$ dimers are filtered into the urine and reabsorbed by renal tubular cells; hemoglobinuria results when reabsorptive capacity is exceeded. Iron is embedded in hemosiderin within the tubular cells; some of the iron is assimilated for reutilization and some reaches the urine when the tubular cells slough.

cell alloantibodies), and anemia is compounded by reticulocytopenia, not due to parvovirus B19 or red cell aplasia. The red blood cells break down at a faster rate. This is particularly common in patients with co-existent G6PD deficiency. While patients with an $\mathrm{Hb}$ level of 6-7 g/dL who are able to participate in daily routine activities in a normal fashion are not uncommon, their tolerance for exercise and exertion tends to be very limited. In extravascular hemolysis, RBCs are phagocytized by macrophages in the spleen and liver. Causes include RBC membrane abnormalities such as bound immunoglobulin, or physical abnormalities restricting $\mathrm{RBC}$ deformability that prevent egress from the spleen. Extravascular hemolysis is characterized by spherocytes.

Hyperhemolysis is dangerous because both transfused and autologous red blood cells are destroyed. Hemoglobin counts after transfusion are, therefore, lower than before transfusion, and further red cell transfusion exacerbates ongoing hemolysis. ${ }^{39,58,64,65}$

Aplastic crises: these are acute worsenings of the patient's baseline anemia, producing pallor, tachycardia, and fatigue. This crisis is triggered by parvovirus B19 (B19V), which directly affects erythropoiesis (production of red blood cells) in bone marrow, resulting in cessation of erythropoiesis. Parvovirus infec- tion nearly completely prevents red blood cell production for 2-3 days. Coupled with greatly shortened RBC lifespan, usually 10-20 days, a very rapid drop in Hb occurs. In normal individuals, this is of little consequence, but the shortened red cell life of SCD patients results in an abrupt, life-threatening situation. The condition is self-limited, with bone marrow recovery occurring in 7-10 days, followed by brisk reticulocytosis. Most patients can be managed supportively; some need blood transfusion.

Megaloblastic changes: anemia may be complicated with megaloblastic changes secondary to folate deficiency. These result from increased red blood cell turnover and folate utilization. Periodic bouts of hyperhemolysis may occur. Management is supportive, sometimes with blood transfusions

Jaundice: jaundice or yellowing of the skin, eyes, and mouth is a common sign and symptom of SCD. Sickle cells do not live as long as normal red blood cells and, therefore, they are dying more rapidly than the liver can filter them out. The breakdown of red blood cells produces a substance called bilirubin. Bilirubin is responsible for yellowing of the skin and eyes (jaundice) in people with sickle cell anemia. 


\section{Painful crises}

Vasoocclusive phenomena and hemolysis: occlusion of the microvasculature by sickled erythrocytes is the most common clinical painful crisis and hallmark of SCD during adult life. ${ }^{66}$ This process leads both to typically self-limited episodes of pain as well as a panoply of end-organ damage, including acquired functional asplenia, sickle cell nephropathy, hepatic sequestration, acute chest syndrome, priapism, pulmonary emboli, osteonecrosis, and ultimately damages every organ system including the retinae, liver, and kidneys. The crisis is precipitated by factors such as infection ( $25 \%$ of incidences); human parvovirus B19 (common viral cause); cold weather due to reflex vasospasm, and dehydration in warm weather. Its symptoms, which are recurrent painful crises and sudden onset of pain in a variety of organs including the extremities, long bones, abdomen, chest, back and joints, occur in children under 18 years. It can lead to fever, malaise, leukocytosis, hypoxia, ischemia, ultimately tissue damage, lifelong disabilities and/or early death. Miller, Sleeper, Pegelow, et al. are of the opinion that painful vaso-occlusive complication of SCD is more likely to have adverse outcomes in later childhood, including death, stroke, frequent pain, and recurrent acute chest syndrome (ACS). ${ }^{67}$

The clinical manifestations of vasoocclusion result from a dynamic combination of abnormalities in hemoglobin structure and function, red blood cell membrane integrity, erythrocyte density, endothelial activation, microvascular tone, inflammatory mediators, and coagulation factors. Tissue injury is usually produced by ischemia and infarction. The organs at greatest risk are those with venous sinuses where blood flow is slow and oxygen tension and $\mathrm{pH}$ are low (e.g. spleen and bone marrow) or those with a limited terminal arterial blood supply (e.g. eye, head of the femur and humerus). No tissue or organ is spared from this injury. Symptoms of the hypoxic injury may be either acute (e.g. painful events, acute chest syndrome) or insidious in onset (e.g. aseptic necrosis of the hips, sickle cell retinopathy). The effects of acute and chronic tissue injury may ultimately result in failure of organs like the kidney, particularly as the patient ages.

The frequency, severity, and duration of these crises vary considerably. It may last several hours to several days and terminate as abruptly as it began. Severe painful crises are treated with hydration and analgesics (PCA), as well as intravenous opioid administration at regular intervals until the crisis has settled. Diphenhydramine is sometimes effective for the itching associated with the opioid use. Incentive spirometry, a technique to encourage deep breathing to minimize the development of atelectasis, is recommended. NSAIDs (such as diclofenac or naproxen) may be used in the management of milder crises.

Central nervous system: another painful crisis is the central nervous system (CNS) complication. Complications involving the central nervous system are among the most devastating manifestations of SCD. The most commonly reported neurological complications for SCD are overt stroke and increased blood flow to the brain. ${ }^{46} \mathrm{~A}$ high frequency of silent infarction, leukoencephalopathy, and cerebral atrophy, is revealed by screening neuroimaging studies in asymptomatic SCD patients. The high prevalence of these findings in the youngest SCD patients underscores the fact that CNS injury begins early in life. Ischemic stroke is the most common brain injury and accounts for about $12 \%$ of deaths in children with SCD (mean age eight years). ${ }^{38}$ The most common intracranial vessels affected are the distal internal carotid, proximal middle cerebral, and anterior cerebral arteries. Vasculopathy of these large vessels is most often associated with cortical infarction.

Other manifestations of cerebral insult, such as neurocognitive delay and behavior difficulties, are also frequently reported in this patient population. The use of transcranial Doppler ultrasonography screening allows the identification of patients at high risk for clinical stroke as well as stroke prevention by chronic transfusion. ${ }^{38}$

Acute chest syndrome: this is a spectrum of pulmonary pathology, characterized by a new pulmonary infiltrate on chest X-ray, often associated with an increased oxygen requirement, respirophasic pain, fever, tachypnea, cough, wheezing, and dyspnea. It is an acute multifactorial process and life-threatening complication of sickle cell anemia. Common causes include lung infection (Chlamydia pneumoniae, Mycoplasma pneumoniae, and respiratory syncytial virus), pulmonary infarction, sickle cells blocking blood vessels, bone marrow or fat embolism, and surgical procedures. At the level of the pulmonary endothelial cell, an imbalance between adhesive forces and nitric oxide is created, favoring intrapulmonary sickle cell adhesion. In SCDs, the incidence of ACS is $33 \%$ in patients with $\mathrm{Hgb} \mathrm{S}-\beta^{0}$ thalassemia, $50 \%$ in patients with $\mathrm{Hgb} \mathrm{SC}$, and $25 \%$ or less in patients with $\mathrm{Hgb} \mathrm{S}-\beta^{+}$thalassemia. ${ }^{68} \mathrm{Up}$ to $20 \%$ of children in the peri-operative period will have an episode of ACS, with the highest risk being the age group between two and four years. ${ }^{69}$ ACS usually develops 48 to 72 hours after the surgical procedure and may not be immediately obvious. ACS is the second most common complication of SCD, with a rate of 12.8 cases per 100 patient years, and is the leading cause of death, being responsible for up to $25 \%$ of sickle cell deaths. ${ }^{70}$ The mortality rate in children is $1.1 \%$ and $3 \%$ overall. ${ }^{71}$

Abdominal complications in SCD include hepato-biliary complications, high incidence of gallstones caused by the continual high levels of bilirubin excretion consequent to chronic hemolysis, acute and chronic cholelithiasis, acute splenic sequestration, duodenal ulcer, and renal failure.

Hepato-biliary complications occur predominantly in patients with homozygous sickle cell anemia, and to a lesser extent in patients with sickle cell trait, Hb SC disease and $\mathrm{Hb} \mathrm{S}$ b thalassemia. The hepatic disorder may primarily be caused by the sickling process, but more commonly arises as a consequence of the multiple transfusions that these individuals require in their lifetime, of the superimposition of hepatitis by hepatotropic or non-hepatotropic viruses, by other infections, cholelithiasis or as a result of vascular phenomena related to the primary disease itself. The term multi-transfusion hepatopathy may, therefore, be more appropriate for these individuals.

Sickle cell hepatopathy encompasses a range of abnormalities arising from a wide variety of insults to the liver and biliary tracts in patients with SCD. These include hepatomegaly, increases in serum bilirubin and transaminase levels, and occasionally increases in the levels of other markers indicative of disorders of the liver and bile canaliculus.

Hepatomegaly was detected at physical examination in $48.9 \%$ of the patients, compared to an incidence of $30.4 \%$ of this finding at ultrasonography. $58,64,72-74$

The direct manifestations of sickle cell disorder in the liver relate predominantly to vascular occlusion with acute ischemia, sequestration, and cholestasis. The main hepatic complications of multiple transfusions include acute and chronic infection with hepatitis B and $\mathrm{C}$ and iron overload. Liver dysfunction may vary from a self-limiting cholestasis to cases of cirrhosis and liver failure; however, severe liver disease rarely occurs in these patients unless other concomitant pathologies, such as infection with hepatitis $\mathrm{C}$ virus (HCV) or human immunodeficiency virus (HIV) are present. . $8,64,73$ Other clinical characteristics suggestive of liver failure are flapping tremor and spider nevi. Liver involvement is not extremely severe.

A further potential consequence of the chronic hemolysis is the development of pigment stones, with consequent cholecystitis and acute and chronic biliary obstruction from choledocholithiasis. Cholelithiasis is more frequent in patients with $\mathrm{Hb} S S$ and $\mathrm{S} / \mathrm{S} \beta 0$ thalassemia electrophoretic patterns, who have higher indirect bilirubin levels, and is less common in Hb SC patients, in whom hemolysis and consequently indirect hyperbilirubinemia are less severe. ${ }^{75}$

Extremities: other painful crises are those involving the extremities - ulcers, aseptic necrosis, and priapism among others. Skin 
ulcers are chronic painful open sores on the legs. They result from minor injury to the area around the malleoli. Because of relatively poor circulation, compounded by sickling and microinfarcts, healing is delayed and infection is established.

Infarction of the penis is a condition called priapism. Priapism is a sustained, painful, and unwanted erection of the penis that pathophysiologically is the result of either increased arterial inflow (i.e., high flow) or, more commonly, the failure of venous outflow (i.e., low flow), resulting in blood trapping within the erectile bodies. ${ }^{18}$ It tends to occur repeatedly. Priapism can be classified as prolonged if it lasts for more than three hours or as stuttering if it lasts for more than a few minutes but less than three hours and resolves spontaneously. Stuttering episodes may recur or develop into more prolonged events. Prolonged priapism is an emergency that requires urological consultation. Recurrent episodes of priapism can result in fibrosis and impotence, even when adequate treatment is attempted.

During pregnancy, intrauterine growth retardation, spontaneous abortion, and preeclampsia may occur. Pregnancy represents a special area of concern. The high rate of fetal loss is due to spontaneous abortion. Placenta previa and abruption are common due to hypoxia and placental infarction. At birth, the infant is often premature or has low birth weight.

\section{Chronic organ damage}

Chronic organ damage: these are splenic sequestration crises, acute papillary necrosis in the kidneys, opthalmological complications, avascular necrosis (aseptic bone necrosis) and pulmonary complications

Splenic sequestrations are acute, painful enlargements of the spleen in the latter part of the first year of life due to pooling of large numbers of sickled cells. The abdomen becomes bloated and very hard. Severe acute splenic sequestration produces hypovolemia and cardiovascular decompensation. The spleen undergoes repeated infarction. After repeated episodes of splenic sequestration, the spleen becomes scarred, fibrotic, shrinks and is permanently damaged. Most children, by the age of eight years old, do not have a functioning spleen either from surgical removal, or from repeated episodes of splenic sequestration. Spleen is non-functional. Management is supportive, sometimes with blood transfusion. Overwhelming post-(auto)splenectomy infection (OPSI), which is due to functional asplenia, is caused by encapsulated organisms such as Streptococcus pneumoniae and Haemophilus influenzae. Daily penicillin prophylaxis is the most commonly-used treatment during childhood, with some hematologists continuing treatment indefinitely. Patients benefit
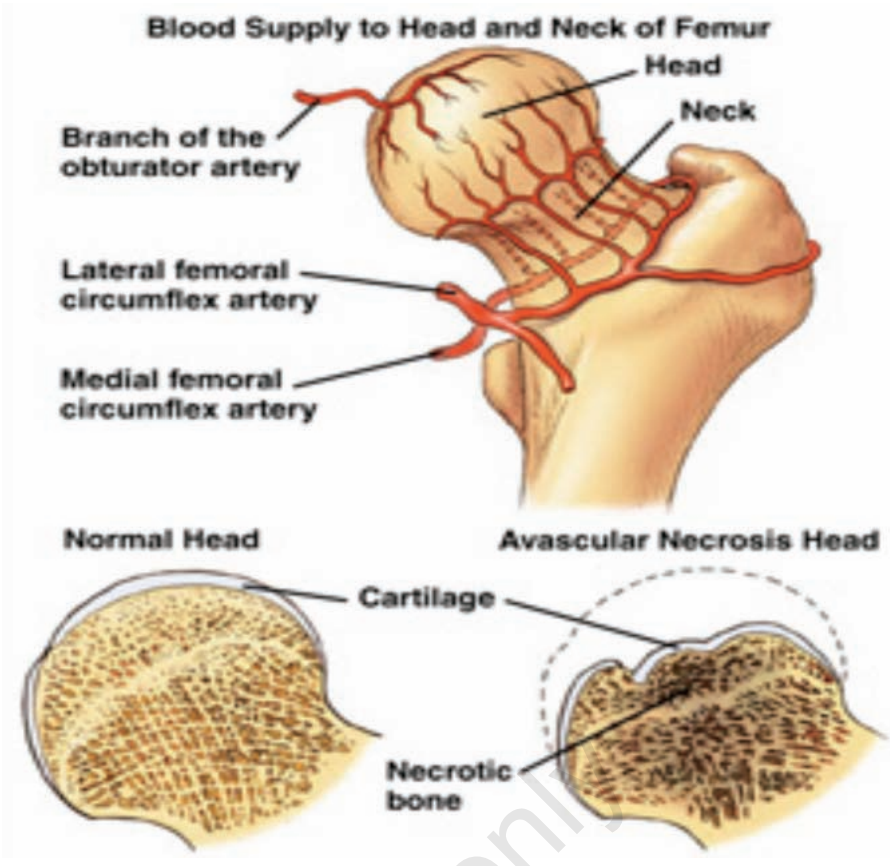

Figure 11. Avascular necrosis (osteonecrosis) of bone. Avascular necrosis of the hip occurs when blood flow to the top portion of the thighbone (femur) is interrupted. The affected portion of the bone consists of the head (the ball-shaped piece of bone that fits into the socket of the hip) and neck (the portion of the thighbone just below the head). When it's deprived of blood, this part of the bone begins to "die," breaking down and causing the cartilage on top of it to collapse.

today from routine vaccination for $H$. influenzae, S. pneumoniae, and Neisseria meningitidis.

Acute papillary necrosis in the kidneys: the internal environment of the kidney is particularly prone to damage from sickle cells. Signs of kidney damage can include blood in the urine, incontinence, and enlarged kidneys. Adults with SCD often experience insufficient functioning of the kidneys, which can progress to kidney failure in a small percentage of adult patients. Nephrotic syndrome is uncommon but may occur. ${ }^{76}$

Opthalmological complications: paraorbital facial infarction may result in ptosis, when the tiny blood vessels that supply oxygen to the retina, the tissue at the back of the eye, may be blocked by sickle cells, leading to conditions called retinopathy, proliferative retinopathy, vitreous hemorrhages and retinal detachments, resulting in blindness. Regular annual ophthalmology examination is recommended.

Avascular necrosis (aseptic bone necrosis) especially in weight bearing areas such as the femur of the hip and other major joints occur as a result of ischemia, which is repeated infarction of joints, bones, and growth plates. This complication is associated with chronic pain and disability, and may require changes in employment and lifestyle (Figure 11).

Pulmonary complications of sickle cell anemia include reactive airway disease (pulmonary hypertension), pulmonary throm- boembolism, and acute chest syndrome. Pulmonary hypertension (increased pressure on the pulmonary artery), leading to strain on the right ventricle and a risk of heart failure; typical symptoms are shortness of breath, decreased exercise tolerance and episodes of syncope. ${ }^{77}$ This may be due in part to the depletion of nitric oxide. Various studies have found that more than $40 \%$ of adults with SCD have pulmonary hypertension that worsens with age. Intravascular hemolysis, by scavenging nitric oxide and causing endothelial cell dysfunction, may play a role in the development of pulmonary hypertension. Echocardiographic studies have reported that approximately $30 \%$ of screened adult patients with sickle cell anemia have pulmonary hypertension (systolic pulmonary artery pressures (PAP) $\geq 30 \mathrm{~mm}$ $\mathrm{Hg}){ }^{77}$ Recent autopsy studies suggest that up to $75 \%$ of sickle cell patients have histological evidence of pulmonary arterial hypertension at the time of death. ${ }^{78}$ Similarly, retrospective studies have demonstrated that $40-50 \%$ of patients with thalassemia intermedia, ${ }^{79}$ and $10-75 \%$ of patients with thalassemia major, have echocardiographic evidence of pulmonary hypertension..$^{80}$

\section{Clinical severity of sickle cell disor- der symptoms}

The clinical course of sickle cell anemia does not follow a single pattern; some patients have mild symptoms, while others have very 
severe symptoms. Symptoms may be less severe or different in children who have inherited a sickle cell gene from one parent and a different abnormal hemoglobin gene from the other. The clinical symptoms can be precipitated by fever, infection, excessive exercise, temperature changes, hypoxia, and hypertonic solutions. The clinical severity of the symptoms experienced is related to the concentration of $\mathrm{Hb} \mathrm{S}$ in the red blood cell and expression of other hemoglobins, endothelial factors, nitric oxide and other factors.

\section{Etiology of different types of anemia}

Many factors contribute to the occurrence of painless and painful crisis in sickle cell disorders. For instance, anemia which is inadequate production of hemoglobin exists in various forms (nutritional anemia, aplastic or hypoplastic anemia, hemolytic anemia; acute anemia; and chronic iron deficiency anemia) and as such is usually triggered by diverse factors. Nutritional anemia is usually precipitated by deficiency of blood making ingredients such as iron, folate or vitamin B12. Aplastic or hypoplastic anemia is usually triggered by depressed bone marrow activity for red blood cells, white cells and platelets or any combination of them. Acute anemia is usually triggered by rapid blood loss. Chronic iron deficiency anemia is usually precipitated by slow blood loss.

Infections in SCD such as malaria, pneumonia, septicemia, meningitis, osteomyelitis, and aplastic crisis are caused by organisms like plasmodium falciparum, S.pneumoniae (pneumococci), salmonella species, and parvovirus 19.

Other factors which may trigger sickle cell crises include sudden exposure to colder or hotter environment or rainfall, undue physical exertion e.g. sports, low pH or acidity, some reaction to food/others, hypoxia, dehydration e.g. after alcoholic binge, water deprivation, fever, and emotional or mental stress.

\section{Treatment for sickle cell disorders}

The management of SCD continues to be supportive and includes hydration, pain relief, blood transfusion and production of fetal hemoglobin (HbF).

\section{Hydration}

Drinking plenty of water daily ( 8 to 10 glasses) or receiving fluid intravenously (to prevent and treat pain crises).

\section{Blood transfusions}

Blood transfusions may be used for anemia and to prevent stroke. They may also be used to dilute the $\mathrm{HbS}$ with normal hemoglobin to treat chronic pain, acute chest syndrome, splenic sequestration, and other emergencies. Used correctly, transfusion can be life-saving and prevent progressive organ damage. Blood transfusion not only increases the oxygen-carrying capacity of blood but also decreases the percentage of cells capable of sickling. It is recommended that transfusion should be carried out with phenotypically matched, leukoreduced, sickle cell negative blood in order to attain a post-transfusion hematocrit of about $36 \%{ }^{81}$ The complications of transfusion are well known and include allo- and autoimmunization, iron overload, and the transmission of infectious diseases such as hepatitis and HIV. Physicians caring for sickle cell patients must understand specific indications, types of red cell preparations, complications of transfusion therapy, and methods to minimize adverse events.

\section{Bone marrow transplantation}

Bone marrow transplant has been effective in curing some patients with sickle cell disease. The decision to undergo this procedure is based on the severity of the disease and ability to find a suitable bone marrow donor. A considerable number of patients with sickle cell anemia worldwide have undergone successful bone marrow transplantation. ${ }^{82}$ Only selected patients are eligible for the procedure. Even then, bone marrow transplantation was associated with a $5-10 \%$ mortality, mostly from graftversus-host disease.

\section{Production of fetal hemoglobin}

Another approach to reducing the effect of $\mathrm{HbS}$ polymer formation has been to augment the production of fetal hemoglobin (HbF). Through population and clinical observation, it has long been recognized that higher blood $\mathrm{HbF}$ levels correlate with fewer clinical manifestations of SCD. Pharmacological manipulation of $\mathrm{HbF}$ in the therapy of sickling disorders has been proposed since the mid-1950s. To date, several agents have been tried, but the safest and most effective has proven to be hydroxyurea. ${ }^{83}$ The mechanism of increased $\mathrm{HbF}$ production by hydroxyurea is not fully understood. Also, recent studies have found that hydroxyurea contributes to the production of nitric acid, a potent endothelial relaxing factor. ${ }^{84}$

Hydroxyurea is a medication that has recently been developed that may help reduce the frequency of pain crises and acute chest syndrome. It is a cytotoxic and cytoreductive antimetabolite that acts via inhibition of DNA synthesis by inhibiting ribonucleotide reductase. Known pharmacological effects of hydroxyurea that may contribute to this drug's efficacy in SCD include increased red cell content of hemoglobin F levels (which reduces the formation of hemoglobin $\mathrm{S}$ polymers), doserelated cytoreductive effects on neutrophils, increased water content of red cells, increased deformability and successful microvascular navigation of sickled cells, and altered adhesion of red blood cells to endothelium by decreasing the expression of endothelial adhesion molecules. It is associated with signifi- cant decreases in the yearly rate of painful crises, hospital admissions, incidence of chest syndrome, priapism, hepatic sequestration, and blood transfusion requirements by as much as $\mathbf{5 0 \%}$. Hydroxyurea treatment also reduces mortality by $40 \% .{ }^{85}$ Hydroxyurea is indicated for adults with SCD who require three or more hospital admissions for vasoocclusive crises per year, and should also be considered for symptomatic children and for patients with organ dysfunction. The longterm effects of the medication, however, are unknown.

\section{Prophylactic therapy}

Three prophylactic measures have become widely accepted in the management of SCD: penicillin prophylaxis (to prevent infections), immunization against pneumococcal infection, and folate administration (to help prevent severe anemia). The mortality rate due to Streptococcus pneumoniae, sepsis, and meningitis was historically very high in children with SCD under the age of six. This rate has been lowered tremendously by three maneuvers. The first is diagnostic screening for SCD in neonates, with immediate initiation of pencillin VK $125 \mathrm{mg}$ twice daily, increased at the age of three years to $250 \mathrm{mg}$ twice daily and continued until the age of five. The second is immunization with heptavalent pneumococcal-conjugated vaccine at two, four, six, and 12 months of age. The third is immunization with 23-valent pneumococcal polysaccharide vaccine at two and five years of age. ${ }^{86}$ Due to the increased metabolic requirement for folate, this is frequently provided as a supplement at a dose of $1 \mathrm{mg}$ daily, although the adequate dietary intake in the United States appears not to endorse such supplementation.

\section{Implications for counseling and psychotherapy}

The implications of the pathological basis of SCD for counseling and psychotherapy can be viewed on two planes.

\section{Implications for professionals}

The pathological basis of SCD has profound implications for psychotherapists, genetic counselors, psychologists (particularly clinical psychologists) and informal help-givers including the spiritual help-givers. The pathological basis of SCD has generated some questions. Are the psychotherapists and counselors sufficiently equipped to adequately meet the psychological needs of the individuals living with SCD? Are the professionals (such as psychologists and counselors) seeing the need to explore the possibility of blending pharmacotherapy with culturally accepted psychotherapeutic interventions for dealing with pain and promoting a steady state among individuals living with SCD? This article thus becomes useful information in the hands of clinical psy- 
chologists and genetic counselors to assist them in better helping individuals living with SCD from a psychotherapeutic perspective. As a result, professionals should focus on the development of cross-cultural psychotherapeutic measures that will address specific needs of individuals living with SCD.

In addition, the study has also shown the need for a counseling and psychotherapeutic package. Since it has been established that there are certain psychological variables that affect individuals living with SCD, and all of the significant persons around them may not be trained psychologists, it therefore implies that there is the urgent need to train enough psychotherapists with a special focus on SCD. These trained professionals would be able to provide a holistic solution to those who come to them for help.

It is also necessary to develop cross-culturally relevant therapeutic packages that will take into consideration the psychological, cultural and spiritual aspects of individuals living with SCD in order to provide them with holistic care. In other words, an eclectic but harmonious combination of behavioral techniques (therapeutic interventions) and cross-cultural therapeutic techniques could be more potent in achieving desirable therapy outcomes. Even though many organizations are providing counseling and psychotherapy, how many are focused on the psychological aspects of sickle cell disorders? There is also the urgent need for research that would assess the level of counseling and therapy being offered to individuals living with SCD during their crisis state and steady state, whether they are appropriate, and whether they are being implemented properly. Appropriate psychological interventions can profoundly alter sets of beliefs, ways of thinking, affective states and behavior patterns of individuals living with SCD.

\section{Socio-economic implications}

The psychological challenges of SCD also have economic implications among individuals living with the disease and their families. A thorough understanding of these issues is crucial in coming up with appropriate intervention strategies. Understanding the 'enemy' is a critical tool in overpowering him/her.

\section{Recommendation}

The magnitude of SCD in Nigeria and Africa on the whole is alarming. Numerous families have lost loved ones to this red blood cell disorder. Health care providers and policy makers must not be indifferent to it, but rather sensitize the Government to provide equitable and effective treatment facilities for affected persons, encourage early presentation by creating awareness, promote further training of genetic counselors, provide adequate and reliable laboratory diagnostic facilities, and support molecular, clinical and operational research.

\section{Conclusions}

Awareness of SCD is paradoxically low in sub-Saharan Africa as increasing survival and prevalence are a largely recent phenomenon. Greater familiarity with SCD due to increasing survival and prevalence creates a widespread desire to do something about SCD.

Problems in affected families include ignorance, lack of access to good services, frequent child illness and death, increased anxiety, and superstition and stigmatization. African governments should provide equitable and effective treatment facilities for affected persons. There is also the need to train more clinical psychologists and genetic counselors in the psychological aspects of SCD. Trained professionals would be able to craft holistic care for the treatment and management of SCD crisis among individuals living with this disease.

\section{References}

1. Embury SH, Hebbel RP, Mohandas N, Steinberg $\mathrm{MH}$, eds. Sickle cell disease. Basic Principles and Clinical Picture. New York: Raven Press 1994;p.311.

2. Serjeant GR. Sickle cell disease, 3rd ed. New York: Oxford University Press. 2001.

3. Ballas SK. Sickle Cell Pain. Progress in Pain Research and Management. Vol. 11. Seattle, WA: IASP Press 1998.

4. Benjamin LJ, Dampier CD, Jacox A, et al. Guideline for the Management of Acute and Chronic Pain in Sickle cell disease. American Pain Society Clinical Practice Guidelines Series No. 1. Glenview, IL;1999.

5. Benjamin LJ. Nature and treatment of the acute painful episode in sickle cell disease. In: Steinberg MH et al, eds. Disorders of Hemoglobin: Genetics, Pathophysiology, and Clinical Management. Cambridge; 2001:671-710.

6. Benjamin LJ, Payne R. Pain in sickle cell disease: a multidimensional construct. In: Pace B, ed. Renaissance of Sickle cell disease Research in the Genomic Era. London: Imperial College Press 2007:99118.

7. Masom VR. Sickle cell anemia. J Am Med Assoc 1922. 79:1318-20

8. Bauer J. Sickle cell disease: pathogenetic, clinical and therapeutic considerations. Arch Surg 1940;41:1344-62

9. Emmel VE. A study of erythrocytes in a case of severe anemia with elongated and sickle-shaped red blood corpuscles. Arch Intern Med 1917;20:586-98

10. Bunn HF. Pathogenesis and treatment of sickle cell disease. N Engl J Med 1997; 337:762-9.
11. Ballas SK. The sickle cell painful crisis in adults: phases and objective signs. Hemoglobin 1995;19:323-33.

12. Ham TH, Castle WB. Relationship of increased hypotonic fragility and of erythrostasis to the mechanism of hemolysis in certain anemias. Trans Assoc Am Physicians 1940;55:127-32

13. Herrick JB. Peculiar elongated and sickleshaped red corpuscles in a case of severe anemia. Arch Intern Med 1910;6:517.

14. Ingram VM. Gene mutations in human haemoglobin: the chemical difference between normal and sickle cell haemoglobin. Nature. 1957:180

15. Allison AC. Protection afforded by sicklecell trait against subtertian malarial infection. Br Med J 1954;1:290-4.

16. Raphael RI. Pathophysiology and treatment of sickle cell disease. Clin Adv Hematol Oncol 2005;3:492-505.

17. Pauling L, Itano HA, Singer SJ, Wells IC. Sickle cell anemia, a molecular disease. Science 1949;110:543-8.

18. Nagel RL, Platt OS. General pathophysiology of sickle cell anemia. In Steinberg $\mathrm{MH}$, Forget BG, Higgs DR, eds. Disorders of Hemoglobin. Cambridge: Cambridge University Press 2001:494-526.

19. Pathare A, Kindi SA, Daar S, Dennison D. Cytokines in sickle cell disease. Hematology 2003;8:329-337.

20. Stuehr DJ. Mammalian nitric oxide synthases. Biochim Biophys Acta 1999;1411:217-30

21. Cai H, Harrison DG. Endothelial dysfunction in cardiovascular diseases: the role of oxidant stress. Circ Res 2000;87:840-4.

22. Ignarro LJ, Buga GM, Wood KS et al. Endothelium-derived relaxing factor produced and released from artery and vein is nitric oxide. Proc Natl Acad Sci USA 1987;84:9265-9

23. Schechter AN, Gladwin MT. Hemoglobin and the paracrine and endocrine functions of nitric oxide. N Engl J Med 2003;348: 1483-5.

24. Olson JS, Foley EW, Rogge C, et al. NO scavenging and the hypertensive effect of hemoglobin-based blood substitutes. Free Radic Biol Med 2004;36:685-97.

25. Coin JT, Olson JS. The rate of oxygen uptake by human red blood cells. J Biol Chem 1979;254:1178-90.

26. Liu X, Miller MJ, Joshi MS, et al. Diffusionlimited reaction of free nitric oxide with erythrocytes. J Biol Chem 1998;273:1870913.

27. Liao JC, Hein TW, Vaughn MW, et al.. Intravascular flow decreases erythrocyte consumption of nitric oxide. Proc Natl Acad Sci USA 1999;96:8757-61.

28. Fields HL. Pain. New York: McGraw-Hill, 1987. 
29. Cousins MJ. John J. Bonica distinguished lecture. Acute pain and the injury response: immediate and prolonged effects. Reg Anesth 1989;14:162-79.

30. Cousins MJ. Acute post operative pain. In: Wall PD, Melzack R, eds. Textbook of Pain, 3rd ed. New York: Churchill Livingstone. 1994;357-85.

31. Katz N, Ferrante FM. Nociception. In: Ferrante FM, VadeBoncoeur TR, eds. Post Operative Pain Management. New York: Churchill Livingstone. 1993;17-67.

32. McMahon SB, Koltzeninburg M, Wall and Melzack's Textbook of Pain, 5th ed. Elsevier, Churchill Livingstone. 2006.

33. Loeser JD, Butler SH, Chapman CR, Turk DC. Bonica's Management of Pain, 3rd ed. Philadelphia: Lippincott Williams \& Wilkins. 2001.

34. Dunn MJ, Hood VL. Prostaglandins and the kidney. Am J Physiol 1977: 233:F169-F184

35. Ballas SK, Reyes PE. Peripheral neuropathy in adults with sickle cell disease. Am J Pain Med 1997;71:53-8.

36. Benjamin LJ. Nature and treatment of the acute painful episode in sickle cell disease. In: Steinberg $\mathrm{MH}$ et al, eds. Disorders of Hemoglobin: Genetics, Pathophysiology, and Clinical Management. Cambridge 2001:671-710

37. Ahn H, Li CS, Wang W. Sickle cell hepatopathy: clinical presentation, treatment, and outcome in pediatric and adult patients. Pediatr Blood Cancer 2005; 45184-90.

38. National Institutes of Health. The Management of Sickle cell disease. 4th ed. Bethesda, MD: National Heart Lung and Blood, Division of Blood Diseases and Resources, 2002.

39. Serjeant GR. Sickle-cell disease. Lancet 1997;350:725-30

40. Hebbel RP, Eaton JW, Balasingam M, Steinberg MH. Spontaneous oxygen radical generation by sickle erythrocytes. J Clin Invest 1982;70: 1253.

41. Wetterstroem N, Brewer GJ, Warth JA, et al. Relationship of glutathione levels and Heinz body formation to irreversibly sickled cells in sickle anaemia. J Lab Clin Med 1984;103:589.

42. Badaloo A, Jackson AA, Jahoor F. Whole body protein turnover and resting metabolic rate in homozygous sickle cell disease. Clin Sci 1989;77:93-7.

43. Grimble RF, Jackson AA, Persaud C, Wride MJ, Delers F, Engler R. Cysteine and glycine supplementation modulate the metabolic response to tumor necrosis factor alpha in rats fed a low protein diet. [published erratum appears in $\mathrm{J}$ Nutr 1993;123:600]. J Nutr 1992;122:2066-73.

44. Hebbel RP. The sickle erythrocyte in double jeopardy: autoxidation and iron decom- partmentalization. Semin Hematol 1990; 27:51-69.

45. Adragna NC, Lauf PK. Role of nitric oxide derivative, in $\mathrm{K}-\mathrm{Cl}$ activation of low-potassium sheep red blood cells. J Membr Biol 1998;166:157.

46. Reid M Jahoor F. Glutathione in disease. Curr Opin Clin Nutr Metab Care 2001;4: 65-71.

47. Das SK, Nair RC. Superoxide dismutase, glutathione peroxidase, catalase and lipid peroxidation of normal and sickled erythrocytes. Br J Haematol 1980;44:87-92.

48. Gibson JS, Speake PF, Ellory JC. Differential oxygen sensitivity of the $\mathrm{K}+-\mathrm{Cl}$ cotransporter in normal and sickle human red blood cells [see comments]. J Physiol (Lond) 1998;511:225-34,

49. Gibson XA, Shartava A, McIntyre J, et al. The efficacy of reducing agents or antioxidants in blocking the formation of dense cells and irreversibly sickled cells in vitro. Blood1998;91:4373-8

50. Setty BN, Stuart MJ. Eicosanoids in sickle cell disease: potential relevance of neutrophil leukotriene B4 to disease pathophysiology. J Lab Clin Med 2002;139: 80-9.

51. Singhal A, Parker S, Linsell L, Serjeant G. Energy intake and resting metabolic rate in preschool Jamaican children with homozygous sickle cell disease. Am J Clin Nutr 2002;75:1093-7.

52. Prengler M, Pavlakis SG, Prohovnik I, Adams RJ. Sickle cell disease: the neurological complications. Ann Neurol 2002;51: 543-52.

53. Jackson AA, Gibson NR, Lu Y, Jahoor F. Synthesis of erythrocyte glutathione in healthy adults consuming the safe amount of dietary protein. Am J Clin Nutr 2004;80: 101-7.

54. Francis RB. Platelets, coagulation, and fibrinolysis in sickle cell disease: their possible role in vascular occlusion. Blood Coagul Fibrinolysis 1991;2:341-53.

55. Westerman MP, Green D, Gilman-Sachs A, et al. Antiphospholipid antibodies, proteins $\mathrm{C}$ and $\mathrm{S}$, and coagulation changes in sickle cell disease. J Lab Clin Med 1999; 134:352-62.

56. Lee SP, Ataga KI, Orringer EP, et al. Biologically active CD40 ligand is elevated in sickle cell anemia: potential role for platelet mediated inflammation. Arterioscler Thromb Vasc Biol 2006;26:1626-31.

57. Tomer A, Harker LA, Kasey S, Eckman JR. Thrombogenesis in sickle cell disease. J Lab Clin Med 2001;137:398-407.

58. Banerjee S, Owen C, and Chopra S. Sickle cell hepatopathy. Hepatology 2001;33: 1021-8.

59. Inwald DP, Kirkham FJ, Peters MJ, et al. Platelet and leucocyte activation in childhood sickle cell disease: association with nocturnal hypoxaemia. Br J Haematol 2000;111:474-81.

60. Stein PD, Beemath A, Meyers FA, et al. Deep venous thrombosis and pulmonary embolism in hospitalized patients with sickle cell disease. Am J Med 2006;119: 897.e7-11.

61. James AH, Jamison MG, Brancazio LR, Myers ER. Venous thromboembolism during pregnancy and the postpartum period: incidence, risk factors and mortality. Am J Obstet Gynecol. 2006;194:1311-5.

62. Furie B, Furie BC. Thrombus formation in vivo. J Clin Invest 2005;115:3355-62.

63. Aygun B, Padmanabhan S, Paley C, Chandrasekaran V. Clinical significance of RBC alloantibodies and autoantibodies in sickle cell patients who received transfusions. Transfusion 2002;42:37-43.

64. Akyürek Savas N, Akbulut S, Köseoglu T, Albayrak L. Chronic liver disease in a patient with sickle cell anemia. Turk J Gastroenterol 2006;17:252-5.

65. Chui DH and Dover GJ. Sickle cell disease: no longer a single gene disorder. Curr Opin Pediatr 2001;13:22-7.

66. Ballas SK and Lusardi M. Hospital readmission for adult acute sickle cell painful episodes: frequency, etiology, and prognostic significance. Am J Hematol 2005;79:1725.

67. Miller ST, Sleeper LA, Pegelow CH, et al. Prediction of adverse outcomes in children with sickle cell disease. N Engl J Med. 2000;342:83-9.

68. Padron J, Peiro C, Cercas E, et al. Enhancement of S-nitrosylation in glycosylated hemoglobin. Biochem Biophys Res Commun 2000;271:217-21.

69. Nielsen HJ, Reimert CM, Pedersen AN, et al. Time-dependent, spontaneous release of white cell- and platelet-derived bioactive substances from stored human blood. Transfusion 1996;36:960-5.

70. Patel RP. Biochemical aspects of the reaction of hemoglobin and NO: implications for Hb-based blood substitutes. Free Radic Biol Med 2000;28:1518-25.

71. Moya MP, Gow AJ, Califf RM, et al. Inhaled ethyl nitrite gas for persistent pulmonary hypertension of the newborn. Lancet 2002;360:141-3.

72. Charlotte F, Bachir D, Nénert M, et al. Vascular lesions of the liver in sickle cell disease. A clinicopathological study in 26 living patients. Arch Pathol Lab Med 1995; 119:46-52.

73. Mekeel KL, Langham MR Jr. GonzalezPeralta R, et al. Liver transplantation in children with sickle-cell disease. Liver Transpl 2007; 13:505-8.

74. Traina F, Saad ST. Complicações hepáticas na doença falciforme. Rev Bras Hematol Hemoter 2007;29:299-303. 
75. Omonge E, Ogutu EO, Aluoch JR. Clinical and laboratory predictors of cholelithiasis in patients with sickle cell anemia. East Afr Med J 1998;75:347-50.

76. Powars DR, Elliott-Mills DD, Chan L, et al. Chronic renal failure in sickle cell disease: risk factors, clinical course, and mortality. Ann Intern Med 1991;115:614-20.

77. Gladwin MT, Sachdev V, Jison ML, et al. Pulmonary hypertension as a risk factor for death in patients with sickle cell disease. N Engl J Med 2004;350:886-95.

78. Haque AK, Gokhale S, Rampy BA, et al. Pulmonary hypertension in sickle cell hemoglobinopathy: a clinicopathologic study of 20 cases. Hum Pathol 2002; $33: 1037-43$.

79. Aessopos A, Farmakis D, Karagiorga M, et al. Cardiac involvement in thalassemia intermedia: a multicenter study. Blood
2001;97:3411-6.

80. Derchi G, Fonti A, Forni GL, et al. Pulmonary hypertension in patients with thalassemia major. Am Heart J 1999;138: 384.

81. National Heart, Lung, and Blood Institute, National Institutes of Health. The Management of Sickle cell disease (NIH Publication No. 02-2117). Bethesda, MD: NIH, 2002. Available at http://www. nhlbi.nih.gov/health/prof/blood/sickle/; accessed February 13, 2006.

82. Vermylen C, Cornu G. Hematopoietic stem cell transplantation for sickle cell anemia. Curr Opin Hematol 1997;4:377-80.

83. Steinberg MH, Barton F, Castro 0, et al. Effect of hydroxyurea on mortality and morbidity in adult sickle cell anemia: risks and benefits up to 9 years of treatment. JAMA 2003;289:1645-51.

84. Cokic VP, Smith RD, Beleslin-Cokic BB, et al. Hydroxyurea induces fetal hemoglobin by the nitric oxide-dependent activation of soluble guanylyl cyclase. J Clin Invest 2003;111:231-9.

85. Charache S, Terrin ML, Moore RD, et al. Effect of hydroxyurea on the frequency of painful crises in sickle cell anemia. Investigators of the Multicenter Study of Hydroxyurea in Sickle Cell Anemia. N Engl J Med 1995;332:1317-22.

86. American Academy of Pediatrics. Committee on Infectious Diseases. Policy statement: recommendations for the prevention of pneumococcal infections, including the use of pneumococcal conjugate vaccine (Prevnar), pneumococcal polysaccharide vaccine, and antibiotic prophylaxis. Pediatrics 2000;106:362-6. 